\title{
Harnessing the Potential of Plant Transcription Factors in developing Climate-Smart Crops: Future Prospects, Challenges, and Opportunities
}

\author{
Rahil Shahzad $^{\text {* }}$ Shakra Jamil ${ }^{1}$, Shakeel Ahmad², Amina Nisar ${ }^{3}$, Zarmaha Amina ${ }^{3}$, \\ Shazmina Saleem ${ }^{3}$, Muhammad Zaffar Iqbal ${ }^{1}$, Rana Muhammad Atif ${ }^{3}$, Richard Thompson ${ }^{4}$, \\ and Xiukang Wang ${ }^{5^{*}}$ \\ ${ }^{1}$ Agricultural Biotechnology Research Institute, Ayub Agricultural Research Institute, Faisalabad \\ 38000, Pakistan; rahilshahzad91@gmail.com (R.S), shakrajamil29@jamil.com (S.J), \\ dr_zaffariqbal@hotmail.com (M.Z.I). \\ ${ }^{2}$ State Key Laboratory of Rice Biology, China National Rice Research Institute, Hangzhou 310006, \\ China; shakeelpbg@gmail.com \\ ${ }^{3}$ Department of Plant Breeding and Genetics, University of Agriculture, Faisalabad 38000, Pakistan, \\ aminanisar18@gmail.com (A.N), zarmahaamina092@outlook.com (Z.A), \\ shazmeenasaleem@gmail.com (S.S), dratif@uaf.edu.pk (R.M.A). \\ ${ }^{4}$ French National Institutes for Agricultural Research, Paris 75000, France; thompson@dijon.inra.fr \\ ${ }^{5}$ College of Life Sciences, Yan'an University, Yan'an 716000, China; wangxiukang@ yau.edu.cn
}

\section{Correspondence:}

*Correspondence: rahilshahzad91@gmail.com (R.S.), wangxiukang@yau.edu.cn (X.W.)

Keywords: Biotic stress; Abiotic stress; climate change; Plant Transcription Factors; Food Security; Crop Improvement

\begin{abstract}
Crop plants should be resilient to climatic factors in order to feed ever-increasing populations. Plants have developed stress-responsive mechanisms by changing their metabolic pathways and switching the stress-responsive genes. The discovery of plant transcriptional factors (TFs) as key regulators of different biotic and abiotic stresses have opened up new horizons for plant scientists. TFs perceive the signal and switch certain stress-responsive genes on and off by binding to different cis-regulatory elements. The above 50 species of plant TFs have been reported in nature. DREB, bZIP, MYB, NAC, Zinc-finger, HSF, Dof, WRKY, and NF-Y are important with respect to biotic and abiotic stresses whereas the role of many TFs is yet to explore. In this review, we summarize the role of different stress-responsive TFs with respect to biotic and abiotic stresses. Further, challenges and future opportunities linked with TFs for developing climate-resilient crops are also elaborated.
\end{abstract}

\section{Introduction}

Agricultural crops are important as they represent the in terms of largest source of calories (70\%$80 \%)$ and protein $(60-70 \%)$ intake for mankind. However, the changing climate is adversely affecting plant health and causing food insecurity due to activation of multiple biotic and abiotic factors [1]. Plants have adopted different resistance mechanisms for survival under changing environmental conditions. For example, in response to drought stress, plants start developing a strong root system and promote lateral roots to increase the water catchment area. Similarly, in response to terminal heat stress, plants shift their growth patterns from vegetative to reproductive growth to limit the effect of terminal heat stress on reproduction; many other similar examples exist [2]. Plants respond to 
different abiotic and biotic challenges through changes at the molecular, cellular, biochemical, and physiological levels. In many cases, the driving forces behind these changes are genes encoding transcription activators and repressors that regulate expression of downstream stress responsive genes and modulate different developmental and metabolic pathways [3]. During the past couple of decades, extensive research has focused on the identification of the key factors associated with regulating the molecular response to stress signal perception [2].

Transcriptional factors (TFs) are frontline defensive factors of plants against various biotic and abiotic stresses (Figure 1). These play a fundamental roles in plant tolerance/resistance to various abiotic and biotic stresses [2,4]. TFs usually respond to stress by binding their target sites within cisacting elements in promoter regions of stress responsive genes (Figure 1E). TFs binding in promotor regions initiate a complex formation for biochemical, physiological, and molecular responses. The Stress response comprises signal perception, signal transduction, and expression of stress-responsive genes (Figure 1B-D). The stress signal is received by receptors in plant cell membranes, or the cell wall and transduced through intracellular elements, i.e., $\mathrm{Ca}^{2+}$, Reactive Oxygen Species (ROS), phytochromes, phosphatases, and protein kinases to TFs. TFs then control gene expression and initiate expression of stress responsive genes [5].

Plant genomes contain a large complement of TF genes approximately $6 \%$ of total ESTs (Table S1). However, a major roles under biotic and abiotic stresses are played by dehydration responsive element binding (DREB), basic leucine zipper (bZIP) domain, MYB, no apical meristem (NAM), ATAF1/2, and cup-shaped cotyledon (CUC2) (NAC), heat shock factors (HSF), DNA-binding with one ZF-proteins (Dof), WRKY, Nuclear factor Y (NF-Y), and Zinc-fingers. TFs have become central due to the great variety of responses elicited and potent role in both biotic and abiotic stress tolerance, i.e., WRKY TFs simultaneously regulate drought, heat, cold stress, counter disease, as well as pest and nematode attacks [6].

In this review we summarize the current status of different plant TF classes, including DREB, bZIP, MYB, NAC, Zinc-finger, HSF, Dof, WRKY, and NF-Y, and their substantial roles in abiotic and biotic stress responses which may allow development of resistant and/or tolerant crop plants. Different crop improvement techniques, i.e. conventional breeding, mutation breeding, transgenic breeding, and gene editing and silencing are considered and current associated challenges and future opportunities are listed.

\section{Structure, Function, and Mechanism of Action of Various Groups of TFs}

TFs are classified according to the presence of characteristic sequence motifs which correspond in general to their DNA-binding domains (Figure 2). Although there is no strict correlation between sequence type and function, different TF classes tend to have different roles in the hierarchy of responses, although many interact as part of their response, as will be evident from a comparison of the principal classes. 


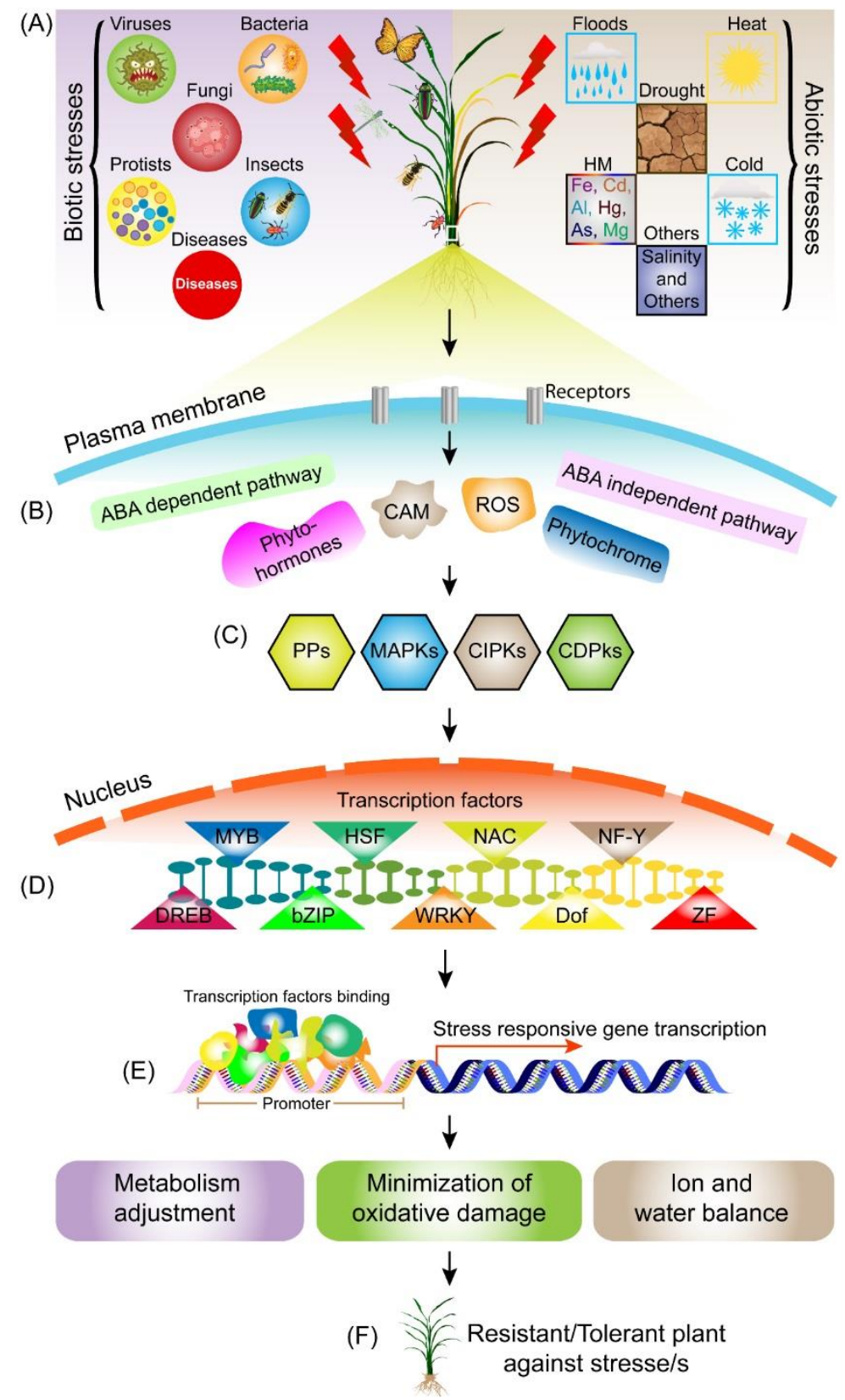

Figure 1. Mechanism of action of transcriptional factors (TFs) in development of resistance in plants against biotic and abiotic stresses. (A) Different biotic and abiotic stresses affect plant growth and development; however, plants have developed rapid response strategies to unfavorable conditions; these involve interconnected networks at the molecular level controlled by signal cascades. The different components of stress responses are (B) signal perception, and (C) signal transduction, (D) transcriptional regulation, (E) gene expression, (F) gene adoption. When plant cells perceive a stress signal, receptors or sensors in the cell wall or membrane detect the stress stimulus, followed by a rapid response that transduces the external signal to intracellular signals. Signal cascades involving intracellular molecules or ions are activated along with kinase cascades, which are generally cytoplasmic. Major cascades are associated with reactive oxygen species (ROS) and calcium ions $\left(\mathrm{Ca}^{2+}\right)$. Phytohormones, including abscisic acid, jasmonic acid, salicylic acid, and ethylene, are powerful second messengers that coordinate signal transduction pathways during stress responses. These signals activate several parallel transduction pathways, which often involve phosphatases and protein kinases. Following the 
initial step of signal perception, plants activate two major signal cascades: the mitogen-activated protein kinase (MAPK) and calcium-dependent protein kinase (CDPK) pathways. Finally, specific TFs are upregulated or downregulated by protein kinases or phosphatases, and the TFs bind to cis-elements of stress-related genes to enhance or suppress their transcription. Finally, stress resistant/tolerant plants emerge.

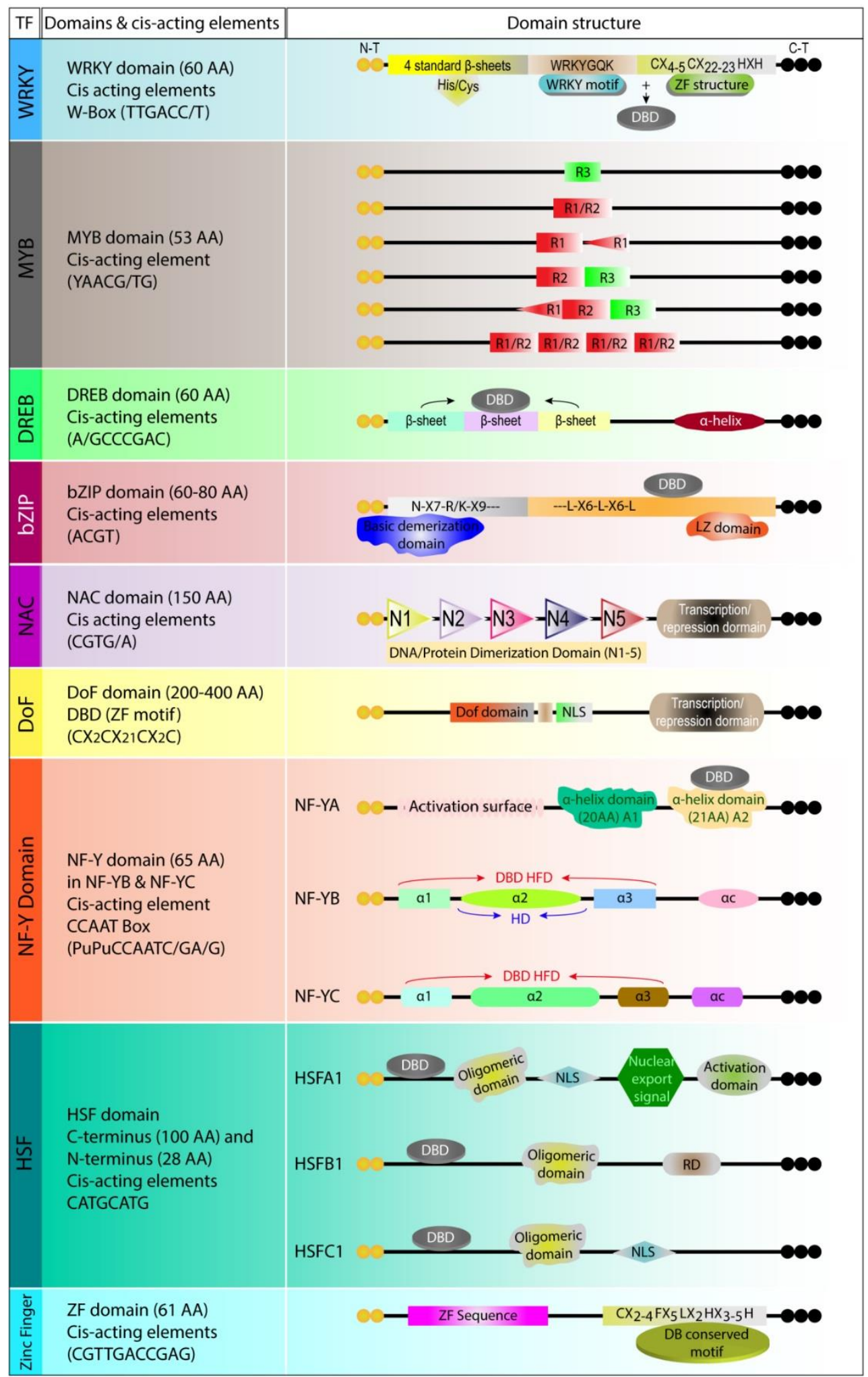


Figure 2. A detail description of Domain structure, domain composition, and cis-regulatory elements of nine TFs, i.e., WRKY, MYB, DREB, bZIP, NAC, Dof, NF-Y, HSF, and Zinc finger. WRKY: The WRKY TFs contains the N-terminal WRKYGQK domain, while at the C-terminal, Zinc Finger $(\mathrm{ZF})$ motifs are present. The ZF-motif may be either $\mathrm{Cx} 4-5 \mathrm{Cx} 22-23 \mathrm{HxH}$ or Cx7Cx23HxC. The WRKY domain spans around 60 amino acids and is a DNA binding protein, which binds to W-BOX (TTGACT/C) and many other binding sites [7-11]. MYB: The MYB domain consists of 52 amino acids repeats forming $3 \alpha$-helicase, in which the second and third helicase form helix structure with three equally spaced tryptophan, forming hydrophobic core in a three-dimensional (3D) helix structure. The third helix is the "recognition helix" that directly binds to DNA and inserts it into a major grove. Two MYB repeats are bind in the major grove and recognize specific DNA target sequence during DNA contact [12,13]. DREB: The DBD of family members is the AP2/ERF type with a conserved region of 60 amino acids; AP2 family members have $\alpha$-helix and $\beta$-sheet stretches at a highly conserved region, the latter within the DBD. DREB proteins attach with C-repeat sequence (A/GCCGAC) or dehydration responsive elements (DRE) for activation of stress responsive genes [14-16]. bZIP: The bZIP domain is made up of a basic region at the N-terminal linked to C-terminal leucine zipper. About 16 amino acids are present in the basic region, which form an invariant motif $(\mathrm{N}-\mathrm{x} 7-\mathrm{R} / \mathrm{K})$ that is responsible for binding to DNA. The bZIP domain consists of two structures: N-x7-R/K-x9 (DNA binding site) and leucine zipper (hydrophobic amino acids, i.e., Val, Met with heptad repeats of Leu) [17,18]. NAC: The NAC domain spans approximately 150 amino acids, and has five conserved subdomains (N1-N5) that form motifs for protein-protein interaction, DNA binding, or TF dimerization. Structural studies have shown that DBD is located at N-terminal while regulatory domain is located at the C-terminal [19,20]. DOF: The Dof domain is bi-functional domain, having dual activity for DNA-binding as well as protein-protein interaction. A single ZF-is present in the $\mathrm{C} 2 / \mathrm{C} 2$ domain needed for binding the target 5'-(T) AAAG-3' sequence or its reversibly orientated sequence, CTTT, with a conserved region of target DNA sequence. The Cterminal region helps in regulation of the transcription process by interacting with different regulatory proteins. [21,22]. NF-Y: NF-YA has two domains with $\alpha$ helix structure. The Nterminal conserved region has 20 amino acids $\alpha$ helix A1 domain responsible for interaction with NF-YB and NF-YC, while the C-terminal which binds with the CCAAT element has a 21 amino acid $\alpha$-helix A2 domain. NF-YB and NF-YC, is formed through the Histone Fold Domain. These domains bind with each other through head to tail. Subgroups of NF-Y are NF-YA, NF-YB, and NF-YC, binds to the CCAAT box [23-25]. HSFs: Conserved regions of HSFs include three helical structures an $\mathrm{N}$-terminal DBD with four inverted $\beta$-sheets arranged in parallel fashion. The binding sites sequence termed heat responsive elements (5'-AGAAnnTTCT-3') is recognized by the DBD hydrophobic region, which has a helix-turn-helix conformation. At the N-terminal, the oligomeric domain contains two regions of hydrophobic heptapeptide repeats HR-A and HR-B, having five and six heptapeptide repeats, respectively [26-29]. Zinc Finger: Most plants ZF genes have conserved the QALGGH amino acid motif within the ZF domain that forms a Q-type C2H2 plant specific ZF subfamily. This motif is present at the $\mathrm{N}$ terminal on an alpha helix. The ZFmotif has zinc, along with two cysteine and two histidine molecules at base, and one alpha helix or two beta-pleated sheets arranged in anti-parallel fashion in a finger like projection. ZFs play role in sub cellular localization and stress responses [30-33].

\section{Role of Transcription Factors under Abiotic Stresses}

Global warming is becoming an increasing threat to crop productivity as it exposes crops to a plethora of stresses, i.e., drought, heat, flooding, salinity, and heavy metal stress. These environmental factors are menacing crop survival. Abiotic factors affect growth, productivity, and 
development of plants, and can reduce up to $50 \%$ yields of wheat, rice, maize, and cotton [19]. Plants respond to stress by certain physiological adjustments, i.e., increasing ion fluxes, production of ROS, accumulation of amino acids and soluble sugars, maintaining homeostasis and osmotic potential, and change in phytohormone concentrations (Figure 1B). The stress-related receptors receive environmental stimuli and activate the stress responsive genes [34]. The role of different genes/TFs in response to different stresses is discussed below (Table 1).

\subsection{Drought stress}

Drought is a devastating abiotic stress, which occurs due to shortage of ground water, high temperature, and/or low rainfall. Drought reduces seedling emergence, germination rate, vegetative growth, root \& shoot dry matter, and hypocotyl length [35]. It decreases turgor pressure and limits cell elongation, cell growth, and leaf expansion. Acute shortage of water damages the thylakoid membranes and photosynthetic pigments and slowing the rate of photosynthesis. During drought stress, plants close stomata, thereby reducing intracellular $\mathrm{CO} 2$ concentration thus reducing photosynthesis and also inducing oxidative damage [36]. Plants respond to stress by certain physiological adjustments, i.e., increasing ion fluxes, production of ROS, accumulation of amino acids, and soluble sugars and changes in phytohormone levels. TFs play an important role in orchestrating these processes by activating genes that execute stress responses [34].

WRKY TFs play an important role in improving stress tolerance, particularly drought and heat tolerance in various crop plants. TaWRKY1 and TaWRKY33 in Arabidopsis thaliana increases drought tolerance due to overexpression of downstream stress related genes. AtWRKY1 locates in the nucleus and binds to the W-box domains of AtDREB1A, AtMYB2, and AtAB15 to control their transcription and regulate stomatal conductance [28]; in transgenic Arabidopsis ZmWRKY40, activated stress related genes and generation of ROS. Overexpression of TaWRKY2 in wheat increased drought tolerance and grain yield. Arabidopsis AtWRKY3O overexpression in transgenic wheat increased biomass, plant growth, proline concentration, soluble sugar, protein, relative water content, chlorophyll content, and antioxidant enzymes activities to alleviate drought stress [19]. In Arabidopsis thaliana, the bZIP gene, AtABP9 binds to an ABPR motif and increased photosynthetic activity. It increases production of abscisic acid (ABA) and changes composition of photosynthetic pigments. ZmNF-YB16 overexpresses in young seedling under drought conditions, as a result, antioxidant enzymatic activity increases [34].

Similarly, SlWRKY8 overexpressed under drought conditions activates malondialdehyde (MDA), hydrogen peroxide $\left(\mathrm{H}_{2} \mathrm{O}_{2}\right)$ production, and antioxidant enzymatic activity. These changes trigger SIRD29, SIAREB, and SIDREB2A genes, which decreases stomatal aperture, oxidative pressure, and increases relative water and proline contents to alleviate drought stress. DREB1A overexpressed in Arabidopsis thaliana, resulted in high accumulation of solutes and initiation of late embryogenesis abundant protein [37]. Similarly, soybean GmNAC8 overexpressed under drought stress and binds to GmDi19-3 (drought-induced proteins), which activates proline and superoxide dismutase (SOD) activity. Overexpression of ZmNAC111 increases water use efficiency of drought prone maize seedling by upregulating drought responsive genes [38].

\subsection{Heat stress}

Heat stress adversely affects plant growth and quality by changing their morphological, physiological, and biochemical features. It decreases chlorophyll content and simultaneously induces oxidative stress due to accumulation of hydroxyl $\left(\mathrm{OH}^{-}\right)$, hydroperoxyl $\left(\mathrm{HO}^{2-}\right)$, alkoxy $\left(\mathrm{RO}^{-}\right)$, and superoxide $\left(\mathrm{O}^{2-}\right)$ radicals. Oxidative stress hinders photosynthesis and respiratory activities, disrupts 
protein structure, and membrane integrity [39]. Heat stress causes burning of leaves and branches, patch formation on leaves, reduction in germination and growth, reduced tillering, and reduction of grain size and grain yield [36]. Elevated temperature uplifts the rate of transpiration, which adversely affects root growth. Sucrose phosphate synthase, adenosine diphosphate-glucose pyro-phosphorylase, and invertase are highly sensitive enzymes that disturb sucrose and starch synthesis pathways during heat stress. On the other hand, high temperature increases catalytic activity of Rubisco, but decreases its ability to bind with $\mathrm{CO}_{2}$ and $\mathrm{O}_{2}$, and slows down the photosynthetic rate [40].

Triticum aestivum, Solanum lycopersicum, Cicer arietinum, Glycine max, and Sorghum bicolor are heat-sensitive crops. Similarly, pollens formation, seed setting, and grain filling are highly heatsensitive plant processes [41]. Plants have several adaptations against heat stress, i.e., degradation of oxyradicals, reduction in the lipid membrane transformation stage, and biological metabolism. Epigenetic modifications, i.e., acetylation, methylation, phosphorylation, and ribosylation also help plant survival during heat stress by modifying histone proteins after translation [42]. Another modification is evolution of heat shock factors (HSFs). HsfA1s are prime activators in response to heat stress, while in non-stress conditions; these are suppressed by heat shock proteins, i.e., HSP70 and HSP90. These regulate expression of some TFs, i.e., dehydration responsive element binding $2 \mathrm{~A}$ (DREB2A), heat shock factors A2 (HsfA2), heat shock factor B (HsfBs), DREB2C, multiprotein binding factor $1 \mathrm{C}(M B F 1 C)$, and NAC. HSPs are involved in homeostasis at the cellular level and plant defence. At the onset of heat stress, inactive HSFs are activated through oligomerization and shuttle signalling between the cytoplasm and nucleus [43].

HSP70 makes a complex with heat stress RNA1 (HSR1) and translation elongation factor (eEF1A), which activates HSF1. HSF1 then activates the cell heat stress responsive machinery [44]. A complex of TFs network consisting of MYB, bZIP, NAC, and a homeobox linked with Leucine zipper is recognized as effective elements in long-term heat stress conditions. General heat stress responsive elements and stabilizers for protein metabolism are HSP10s, HSP20s, HSP60s, HSP90s, and cochaperones [45]. Different WRKY i.e., AtWRKY18, AtWRKY25, AtWRKY33, AtWRKY40, and AtWRKY46 also have roles to play during heat stress. AtWRKY39 imparts heat stress tolerance in Arabidopsis thaliana by binding to a calmodulin binding TF [46]. The AtDREB2A binds to dehydration responsive elements (DRE) at the promoter site of AtHSFA3, and activates a stress response through an ABA-independent pathway [47].

\subsection{Salinity stress}

Around $30 \%$ of arable land is affected by salt stress and the proportions continue to increase at a rapid pace due to urbanization. Salt stress inhibits imbibition, and decreases root elongation and germination percentage [48]. Salinity and osmotic stress are related and plants have to undergo drought stress in media or soil causing salt stress [49]. Osmotic stress closes stomata, decreases photosynthetic rate, and disrupts action of the thylakoid membrane or Calvin cycle enzymes [50]. It alters leaf anatomy, i.e., thickness of epidermis, mesophyll, palisade length, and diameter. Plants start producing $\mathrm{ROS}\left(\mathrm{O}^{2-}\right.$ ion, $\mathrm{H}_{2} \mathrm{O}_{2}$ and $\left.\mathrm{OH}^{-}\right)$in chloroplast, cytosol, apoplastic space, and mitochondria. Activation of ROS results in oxidation of carbohydrates, lipids, proteins, nucleic acid, and impacts membrane integrity. $\mathrm{OH}^{-}$ion causes damage to DNA by disrupting purine and pyrimidine [51]. Plants maintain homeostasis within and outside the cytoplasm for normal growth [52]. Proteins, channel protein anti porters and symporters, maintain ion transport during homeostasis. Moreover, compatible osmolytes, i.e., free amino acid sugars, quaternary ammonium compounds, and proline are produced [53]. These osmolytes help in protection of cell structure and maintain osmotic balance by continuous water flux. Glycine betaine, an organic compound, plays a significant role in lowering salt stress by osmotic adjustment, protecting photosynthetic machinery, and protein stabilization. 
Various antioxidant enzymes, such as superoxide dismutase (SOD), ascorbate peroxidase (APX), glutathione reductase (GR), glutathione peroxidase (GPX), and non-enzymatic antioxidants, such as carotenoids and tocopherols, act as scavengers against ROS [51]. All of these events are regulated by a large number of salt responsive genes controlled by different TFs, which percept signal and start defense mechanism [54].

Three types of genes play roles in responses to salt stress, which includes genes of sensing and signaling stress, transport regulators, and salt stress-response-related genes. When stress occurs, $\mathrm{Na}^{+}$ ion enters the cell via non-selective cation channels and other membrane transporters. These $\mathrm{Na}^{+}$ions are recognized by unknown sensory elements. In the second step, $\mathrm{ROS}, \mathrm{Ca}^{2+}$, and other hormones act as secondary messengers against salt stress and induce altered transcriptomic profile [55]. AtNAC2, a nuclear localized gene, is upregulated during salt stress; it promoted lateral root development [56]. Similarly, over-expression of AtWRKY46 increases lateral root development through an ABA signaling pathway. Overexpression of Gossypium hirsutum derived GhWRKY34 in Arabidopsis increased salt tolerance by inducing selective uptake of $\mathrm{Na}^{+}$or $\mathrm{K}^{+}$ions in roots and leaves [57]. Moreover Reaumuria trigyna derived RtWRKY1 is overexpressed under salt stress and resulted in increased root growth, increased antioxidative enzymes, decreased $\mathrm{Na}^{+}$or $\mathrm{Na}^{+} / \mathrm{K}^{+}$ratio [58]. Overexpression of GmWRKY54 alleviates salt stress in soybean [59]. AtbZIP24 increases salt tolerance by osmotic balance, ion homeostasis in cytoplasm, and increased growth and development, involving homo- and heterodimerization, or post-transcriptional modification [60]. Overexpression of GmERF3 in tobacco increased free proline and soluble carbohydrates and relieved salt stress.

\subsection{Cold stress}

Cold stress affects cellular metabolism by decreasing the rate of biochemical reaction, concentration of nucleic acid, and protein. Plants respond to cold stress by increasing proline contents, membrane fluidity, and ROS activation [61]. ROS causes oxidative damage in cells, reduced enzymatic activity, cause ionic imbalance, damaged cell membranes, reduced respiration rate, and degraded proteins. Plants also face low germination, delayed cell cycle, low leaf development rate, decreased seedling vigor, and yield [62]. Root development is also affected, resulting in lowered biomass and root length, and reduced root volume. Onset of cold stress at the reproductive stage leads to pollen sterility, abortion of flower or ovules, distortion of pollen tubes, poor fruit setting, deformation of panicles, spikelet degeneration, and reduced productive tillers [63]. The photosynthetic rate decreases due to reduced $\mathrm{CO}_{2}$ conductance in the mesophyll and stomata, restricted transport of metabolites and increased photo-inhibition [62].

Different TFs respond to cold stress by regulating expression of cold responsive genes, dehydrin, abscisic acid responsive genes, and late embryogenesis abundant genes. These TFs are present in the nucleus through as they possess nucleus-localization signals (NLSs). Under stress, membrane bound TFs are activated, enter the nucleus, and regulate gene expression. Nuclear-localized SINACl activate stress responsive genes and enhances cold tolerance. Similarly, ZmSNAC1, OsNAC5, and TaNAC57 genes are overexpressed and enhance cold tolerance (Li et al., 2014). Arabidopsis thaliana and grapevine calli show overexpression of VaWRKY12 and regulated expression of the genes encoding antioxidant enzymes, glutathione S-transferases, and peroxidase [64]. OsWRKY71 was upregulated in rice under cold stress. Overexpression of $C S W R K Y$ enhanced cold tolerance by affecting root development, germination rate, seed development, flowering, and dormancy in cucumber [65]. OsbZIP73 upregulates and plays an important role at flowering, seedling, and reproductive stages to counter cold stress. It co-expressed with $O s b Z I P 71$ and enhanced seed set by affecting pollen fertility through an increase in concentration of soluble sugar in pollen and a decreased level of ABA in anthers [66].

OsbZIP87 and OsbZIP38 also play an important role in enhancing cold tolerance [66]. OsDREB1G regulates expression of cold induced genes present in protoplasts. Arabidopsis thaliana 
AtDREB1A/CBF1 and AtCBF4 are overexpressed in response to cold stress (Moon et al., 2019). MYBs also play important roles in combating cold stress by affecting cell cycle, cellular morphogenesis, hormonal signaling, secondary metabolism, and gene expression. AtMYB14 down regulates under cold stress and encodes the proteins that act as the R2R3-MYB activator. As a result, $\mathrm{CBF}$ proteins $(\mathrm{CBF} 1, \mathrm{CBF} 2$, and $\mathrm{CBF} 3)$ are activated, which initiate cold responsive genes. In transgenic Arabidopsis GmMYBJI is overexpressed and enhances cold tolerance. GmMYBJI regulates expression of many stress responsive genes, such as AtCOR15a, AtRD29B, AtP5CS, and AttCOR78, as a result the plant tolerates cold stress. OsMYB4 in Arabidopsis thaliana is also overexpressed and increases freezing tolerance [67].

\subsection{Heavy metal stress (HMS)}

Heavy metals (HMs) are generally defined as metals with relatively high densities, atomic weights, or atomic numbers, i.e., Mo, Ni, Cd, Cr, and Zn. Heavy metal enriched soil results in reduced growth, altered nutrients and water balance, inhibition of photosynthesis and chlorosis. Further, HMs affect chlorophyll content, photosystem II effectiveness, and Rubisco activity [68]. It leads to drop in reductant pool and less ATP production with less $\mathrm{CO}_{2}$ fixation [69]. Heavy metal enhanced protease activity decreases ammonia glutamate dehydrogenase (GDH), glutamine oxoglutarate aminotransferase (GOGAT), glutamine synthetase (GS), nitrite reductase (NiR), and nitrate reductase (NR) activity [70]. ROS starts accumulating, cause oxidative stress by interacting with proteins, DNA, and lipids, and destabilizing cellular organization [71].

$\mathrm{Cd}$ stimulates the myelin basic protein (MBP) kinase gene and OsMAPK2 in Oryza sativa. Due to heavy metal stress, different mitogen activated protein kinases (MAPKs) are activated, such as in Arabidopsis thaliana induction of $\mathrm{MPK}_{3}$ and $\mathrm{MPK}_{6}$, due to $\mathrm{CuSO}_{4}$ and $\mathrm{CdCl}_{2}$. Oryza sativa multiple stress responsive MK2 (OsMSRMK2), wound and JA-uninducible MK1 (OsWJUMK1), and OsMSRMK3 are induced in presence of $\mathrm{Cd}^{2+}$ and $\mathrm{Cu}^{2+}$ in roots and leaves. Stress activated MAPK (SAMK), Medicago MAP kinase3 (MMK3), Medicago MAP kinase2 (MMK2), and salt stress induced MAPK (SIMK) are activated in Medicago sativa in response to $\mathrm{CdCl}_{2}$ and $\mathrm{CuCl}_{2}$ [72]. Downstream TFs, i.e., activator protein 2 (AP2), WRKY, bZIP, MYB, DREB, ERF, and ZAT $\left(\mathrm{C}_{2} \mathrm{H}_{2}\right.$ type $\mathrm{ZF}$-) transcription factors are stimulated by activation of MAPKs as their targets. Due to Cd and Zn stress, MYB TFs, i.e., AtMYB28, AtMYB72, AtMYB48, AtMYB124, and AtMYB4 are upregulated in Arabidopsis thaliana. A short duration stress of $\mathrm{Cu}$ to roots in Arabidopsis activates AtWRKY22, AtWRKY25, and AtWRKY29, whereas long duration stress of Cd activates AtWRKY25 and AtWRKY29. Similarly, in Glycine max, up-regulation of GmbZIP62 and down-regulation of GmbZIP44 and GmbZIP78 is associated with Cd stress. In Arabidopsis thaliana, Cd stress is responsible for expression of ethylene responsive factors, i.e., AtERF1, AtERF5, and AtZAT6 to regulate plant metabolism [73].

\subsection{Waterlogging stress}

Water logging is a combination of two important stresses: submergence when the whole plant is under water and water logging, when only roots are submerged [74]. Water logging results from prolonged rainfall, poor drainage of soil, and its intensity tends to increase every year [75]. Diffusion of gases in water is low when compared to air, which results in decreased oxygen availability and detrimental effects on plant health [76]. Different physiological and biochemical processes are activated, which shift aerobic respiration to anaerobic fermentation. Moreover, certain toxic compounds, such as alcohol and aldehydes are accumulated in the cytoplasm [77]. There are two stages of water logging, hypoxia (partial depletion of oxygen) and anoxia (complete depletion of oxygen). Different plant processes, i.e., cytoplasmic $\mathrm{pH}$, cellular energy, stem elongation, and adventitious root formation decreases. In addition, fresh and dry mass decrease; and the electrontransport chain and $\mathrm{CO}_{2}$ assimilation are also affected [78]. Furthermore, toxic compounds and ROS 
accumulated. Certain redox enzymes, such as cupredoxins, are activated to maintain ROS balance [79].

Roots also play an important role in response to water logging stress, as aerenchyma and adventitious roots are established. The function of aerenchyma is to increase internal diffusion of oxygen from aerial parts to waterlogged roots to facilitate an aerobic environment [80]. The known transcription factors that play roles in regulation of water logging stress include bZIP, NAC, WRKY, MYB, and ERF families. But the highest number of transcription factors responding to waterlogging stress belong to the MYB and the AP2/EREBP families [81]. Low oxygen-induced genes are characterized by an anaerobic response element (ARE) present in the promoter. ARE has GC and the GT motifs, which are important for gene activity and signal transduction [82]. In Arabidopsis, five ERF VII genes AtHRE1, AtHRE2, AtRAP2.2, AtRAP2.3, and AtRAP2.12 are key regulators of flooding. Rice $S U B 1 A$ is considered a master regulator against water logging stress. These ERF VII tandem repeats are responsible for increasing inter-nodal elongation and enable the plants to overcome waterlogged conditions [80]. ZmEREB180 increases waterlogging tolerance in maize seedlings. ZmEREB180 has a conserved $\mathrm{N}$ terminal motif and its ectopic expression increases tolerance [83]. Overexpression of AtSHYG (AtNAC047) causes hyponastic growth in Arabidopsis [84]. Moreover, SiWRKY51 and SiWRKY65 also play important roles in roots of waterlogged plants [85]. However, exploring the role of TFs under waterlogging stress needs further attention.

\section{Role of Transcriptional Factors under Biotic Stresses}

Biotic stresses such as diseases, insects, and nematodes adversely affect plant growth, development, survival, and crop productivity. Reported losses due to biotic stresses are up to 35\% [19]. Yield losses in USA due to Fusarium head blight and wheat rust amounted to US \$3 billion and US \$5 billion, respectively. In the middle of the $19^{\text {th }}$ century, during the Irish potato famine, the crop were completely destroyed due to late blight (Phytophthora infestans), leaving millions of farmers empty handed [86]. The available data suggest that a decrease in annual crop productivity by arthropods is $18 \%-20 \%$ worldwide, amounting to US $\$ 470$ billion. The area's most prone to biotic stresses are African and Asiatic countries [87]. Disease negatively affects morphological characteristics, i.e., plant height, chlorophyll content, and leaf architecture [88].

To deal with these challenges, the plant adopt coordination of different physiological, biochemical, and molecular processes through signal transduction mechanisms [89]. Pathogen attack signals are recognized through pathogen-associated molecular patterns (PAMPs) present on the host surfaces that trigger a basic immune response PAMP-triggered immunity (PTI). Plants have resistance proteins (R) that directly or indirectly identify effectors and activate effector-triggered immunity (ETI), such as hypersensitive response (HR). The detailed infection process of bacterial, fungal, and viral pathogens, insects, and nematodes, is described below, along with a variety of defense responses for each infection. 
Table 1. Role of different transcriptional factor gene families in abiotic stress tolerance in plants.

\begin{tabular}{|c|c|c|c|}
\hline Stress & Crop & Transcriptional Factors/Genes & Reference \\
\hline \multirow{18}{*}{ Drought } & $\begin{array}{l}\text { Arabidopsis } \\
\text { thaliana }\end{array}$ & 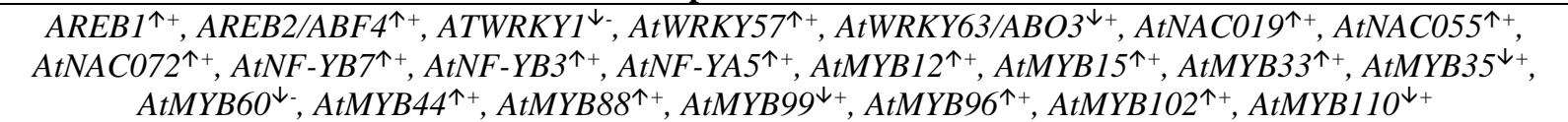 & {$[12,63,90-94]$} \\
\hline & Triticum aestivum & 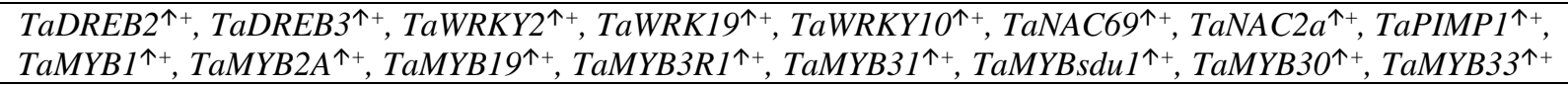 & {$[12,19,63,90-95]$} \\
\hline & Oryza sativa & 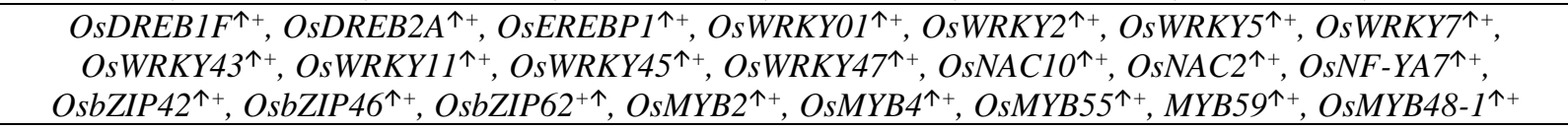 & {$[12,19,63,90-95]$} \\
\hline & Zea mays & 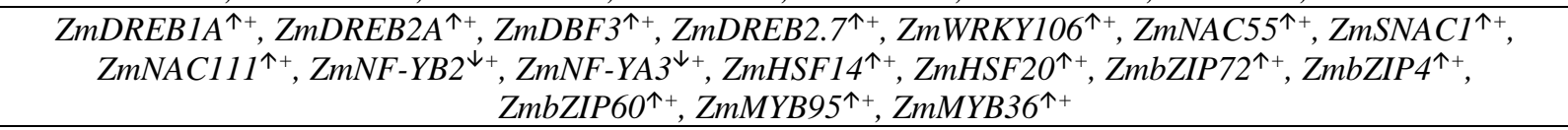 & {$[2,12,19,63,90-96]$} \\
\hline & Glycine max & 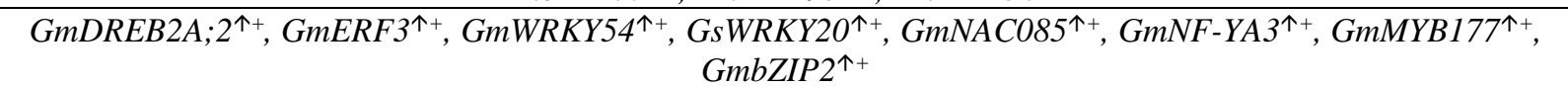 & {$[2,12,19,63,90-96]$} \\
\hline & Vigna radiate & $\operatorname{VrDREB2A^{\uparrow +},\operatorname {VrDREB}2B^{\uparrow +}}$ & [92] \\
\hline & Camellia sinensis & $C s D R E B 2 A^{\uparrow+}, C s D R E B 2 B^{\uparrow+}$ & [92] \\
\hline & Hordeum vulgare & $H v W R K Y 38^{\uparrow+}$ & [90] \\
\hline & $\begin{array}{c}\text { Solanum } \\
\text { lycopersicum }\end{array}$ & $S p W R K Y 1^{\uparrow+}$ & [90] \\
\hline & $\begin{array}{c}\text { Solanum } \\
\text { tuberosum }\end{array}$ & StMYBIR-1 $\uparrow+$ & [97] \\
\hline & Cicer arietinum & CarNAC3 $3^{\uparrow+}$ & [63] \\
\hline & Chrysanthemum & $C m M Y B 2^{\uparrow+}$ & [97] \\
\hline & Setaria italic & SiNF-YAI ${ }^{\uparrow+}, S i N F-Y B 8^{\uparrow+}$ & {$[91,94]$} \\
\hline & Cynodon dactylon & $C d t N F-Y C 1^{\uparrow+}$ & {$[91,94]$} \\
\hline & $\begin{array}{c}\text { Fagopyrum } \\
\text { tataricum }\end{array}$ & $F t b Z I P 5^{\downarrow+}$ & {$[2,98]$} \\
\hline & Poncirus trifoliate & PtrABF ${ }^{\uparrow+}$ & {$[2,98]$} \\
\hline & Vitis vinifera & $V v M Y B 60^{\uparrow+}$ & {$[19,63]$} \\
\hline & $\begin{array}{l}\text { Gossypium } \\
\text { hirsutum }\end{array}$ & GhirNAC2 $^{\uparrow+}$ & [99] \\
\hline \multirow{4}{*}{ Heat } & $\begin{array}{l}\text { Arabidopsis } \\
\text { thaliana }\end{array}$ & 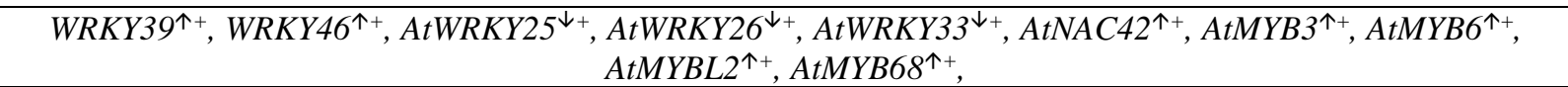 & {$[90,98,100]$} \\
\hline & Oryza sativa & OsDREB2B ${ }^{\uparrow+}$, OsWRKY11 $1^{\uparrow+}$, OsNAC063 $3^{\uparrow+}, O s T Z F 1^{\uparrow+}, O s M Y B 55^{\uparrow+}$ & $\begin{array}{l}{[46,47,90,92,100-} \\
102]\end{array}$ \\
\hline & Zea mays & 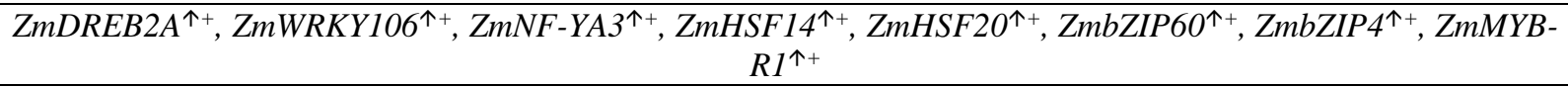 & {$[19,46,47,90,91,102]$} \\
\hline & Glycine $\max$ & GmHSP70 $0^{\uparrow+}, G m D R E B 1^{\uparrow+}$ & {$[102,103]$} \\
\hline
\end{tabular}




\section{Transcriptional factor for climate resilient crops}

\begin{tabular}{|c|c|c|c|}
\hline & Capsicum & $C p D R E B 2^{\uparrow+}$ & {$[102,104]$} \\
\hline & Camellia sinensis & $C s N A M^{\uparrow+}$ & [101] \\
\hline & $\begin{array}{l}\text { Gossypium } \\
\text { hirsutum }\end{array}$ & GhHSF37^+, GhHSF24^+ & {$[102]$} \\
\hline & Capsicum annum & CaHSFA2 $2^{\uparrow+}$ & {$[102]$} \\
\hline & Malus domestica & $M d H S F A-9 b^{\uparrow+}$ & {$[102]$} \\
\hline & $\begin{array}{c}\text { Solanum } \\
\text { lycopersicum }\end{array}$ & 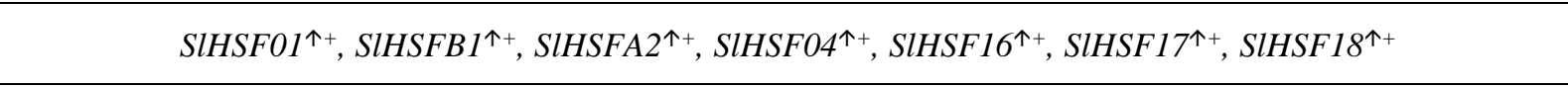 & {$[102,105]$} \\
\hline & $\begin{array}{l}\text { Lycopersicum } \\
\text { esculantum }\end{array}$ & LeAN2 $2^{+}$ & {$[100]$} \\
\hline \multirow{7}{*}{ Cold } & $\begin{array}{l}\text { Arabidopsis } \\
\text { thaliana }\end{array}$ & $D R E B 1 A^{\uparrow+}, A t Z F P 1^{\uparrow+}, A t Z F P 2^{\uparrow+}, A t Z F 3^{\uparrow+}, A t N A C 019^{\uparrow+}, A t M Y B 14^{\downarrow-}, A t M Y B 15^{\downarrow-}$, AtMYB44 $4^{\uparrow+}$, AtMYBC1 $1^{\uparrow+}$ & {$[19,93]$} \\
\hline & Triticum aestivum & TaWRKY19 ${ }^{\uparrow+}$, TaNAC2a $a^{\uparrow+}$, TaNAC4a ${ }^{\uparrow+}$, TaNAC57^+, TaMYB2A ${ }^{\uparrow+}$, TaMYB3R1 $1^{\uparrow+}$, TaMYB56-B ${ }^{\uparrow+}$ & {$[12,65]$} \\
\hline & Oryza sativa & $\begin{array}{c}\text { OsDREBIA }{ }^{\downarrow+}, O s W R K Y 71^{\downarrow+}, O s N A C 6^{\uparrow+}, O s N A C 5^{\uparrow+}, O s N A C 04^{\uparrow+}, O s b Z I P 73^{\uparrow+}, O s M Y B 2^{\uparrow+}, O s M Y B 4^{\uparrow+}, \\
\text { OsMYB3R-2 }\end{array}$ & {$[92,106-108]$} \\
\hline & Zea mays & 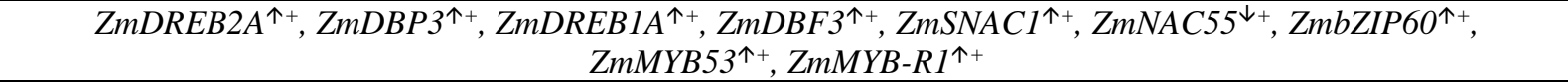 & {$[92,106-108]$} \\
\hline & Glycine max & $G m W R K Y 21^{\uparrow+}, G m N A C 20^{\uparrow+}, G m M Y B 92^{\uparrow+}, G m b Z I P 44^{\uparrow+}, G m b Z I P 62^{\uparrow+}$ & {$[19,65,92]$} \\
\hline & Vitis acerifolia & $\operatorname{VaWRKY12^{\uparrow +}}$ & [106] \\
\hline & Pyrus communis & PcMYB10 $1+$ & [12] \\
\hline \multirow{12}{*}{ Salinity } & $\begin{array}{c}\text { Arabidopsis } \\
\text { thaliana }\end{array}$ & 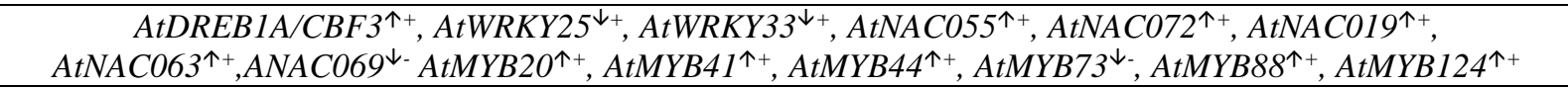 & {$[19,63,109,110]$} \\
\hline & Triticum aestivum & 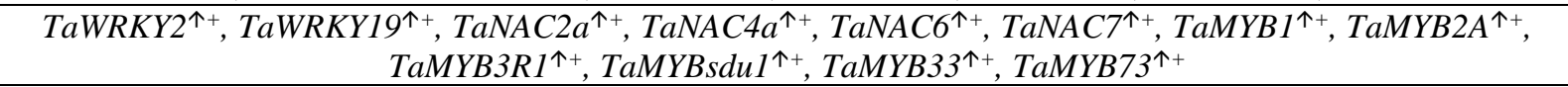 & {$[19,63]$} \\
\hline & Oryza sativa & 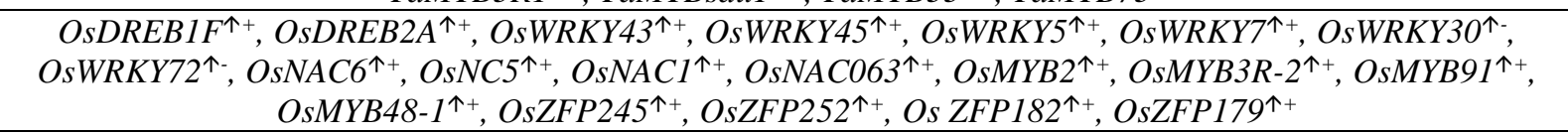 & {$[19,63,109,110]$} \\
\hline & Zea mays & 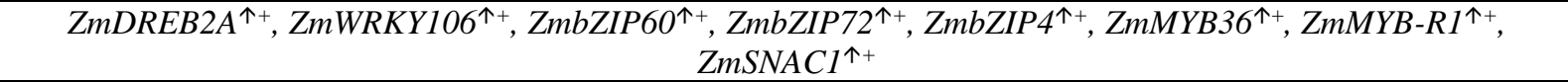 & {$[63,92,93,109]$} \\
\hline & Glycine max & 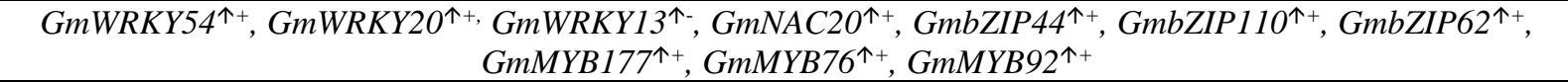 & {$[63,90,92,93]$} \\
\hline & Vigna radiate & $\operatorname{VrDREB} 2 A^{\uparrow+}$ & [109] \\
\hline & Camellia sinensis & $C s D R E B 2 A^{\uparrow+}, C s D R E B 2 B^{\uparrow+}, C s N A M^{\uparrow+}$ & {$[63,109]$} \\
\hline & $\begin{array}{c}\text { Agrostis } \\
\text { stolonifera } \\
\end{array}$ & AsNAC60个+ & {$[63,109]$} \\
\hline & Setaria italic & SiNAC ${ }^{\uparrow+}, \operatorname{SiNF}-Y A 1^{\uparrow+}$ & {$[91,111]$} \\
\hline & Cynodon dactylon & $C d t N F-Y C 1^{\uparrow+}$ & [91] \\
\hline & $\begin{array}{c}\text { Fagopyrum } \\
\text { tataricum }\end{array}$ & FtbZIP5 $5^{\uparrow+}$ & [92] \\
\hline & $\begin{array}{l}\text { Medicago } \\
\text { truncatula }\end{array}$ & $M t M Y B 199^{\uparrow+}, M t M Y B 634^{\uparrow+}, M t M Y B 636^{\uparrow+}, M t M Y B 1070^{\uparrow+}$ & [19] \\
\hline
\end{tabular}




\begin{tabular}{|c|c|c|c|}
\hline & $\begin{array}{l}\text { Gossypium } \\
\text { hirsutum }\end{array}$ & $G h Z F P 1^{\uparrow+}$ & [19] \\
\hline \multirow{4}{*}{$\begin{array}{l}\text { Water } \\
\text { logging }\end{array}$} & $\begin{array}{c}\text { Arabidopsis } \\
\text { thaliana }\end{array}$ & AtNAC102 $2^{\uparrow+}, A t N A C 063^{\uparrow+}, A t A R E B 1^{\uparrow+}$, AtAREB2/ABF4 $4^{\uparrow+}, A t A B F 3^{\uparrow+}, A t A B F 2^{\uparrow+}$ & {$[101]$} \\
\hline & Zea mays & ZmEREB180^+ & {$[101]$} \\
\hline & Camellia sinensis & $C s N A M^{\uparrow+}$ & {$[101]$} \\
\hline & Oryza sativa & OsDREB2A $A^{\uparrow+}$ & [101] \\
\hline \multirow{4}{*}{$\begin{array}{l}\text { Heavy } \\
\text { Metal } \\
\text { Stress }\end{array}$} & $\begin{array}{c}\text { Arabidopsis } \\
\text { thaliana }\end{array}$ & $A t M Y B 48^{\uparrow+}, A t M Y B 28^{\uparrow+}, A t M Y B 72^{\uparrow+}, A t M Y B 124^{\uparrow+}, A t M Y B 4^{\uparrow+}$ & [73] \\
\hline & Zea mays & ZmbZIP54^+ & [19] \\
\hline & Glycine $\max$ & GmbZIP62 $2^{\uparrow+}, G m b Z I P 44^{\downarrow+}, G m b Z I P 78^{\downarrow+}$ & [19] \\
\hline & Triticum aestivum & TaHSFA4a $a^{\uparrow+}$ & [29] \\
\hline
\end{tabular}

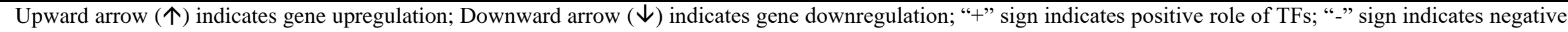
role of TFs, under stress conditions 


\subsection{Bacterial Infections}

More than 200 pathogenic bacterial species have been identified in plants. The most important bacterial infections belongs to genera Pseudomonas, Ralstonia, Agrobacterium, Xanthomonas, Erwinia, Xylella, Pectobacterium, and Dickeya. Pathogenic bacteria produce cell wall degrading enzymes, which provide passage for infiltration and maceration in plant tissue for feeding. Erwinia amylovora causes fire blight of the Rosaceae family, apple, and pear (Mansfield et al., 2012. Ralstonia solanacearum causes bacterial wilt of tomato, tobacco, banana, and the brown rot of potato. Xanthomonas mainly effects rice, banana, tomato, and citrus fruits, and invades mostly xylem or parenchyma tissues [112]. Xylella fastidiosa is a xylem-limited phytopathogen, which causes diseases in grapes, almond, citrus, peach, coffee, and olive trees. Pseudomonas syringea causes infection in the tomato by forming a necrotic lesion surrounded by yellow chlorotic halo on the tomato (termed as bacterial speck) [113].

After a pathogen attack, TFs activate pathogen related (PR) genes and promote HR. HR is responsible for tissue necrosis by systemic acquired resistance (SAR). Defense-related TFs include bZIP, AP2/ERF, NAC, MYB, DOF, and WRKY, which play an important role in defense response against pathogen attacks. Rice $O s W R K Y 80$ and $O s W R K Y 4$ genes increase resistance against sheath blight. OsWRKY 80 attaches to a W-box in the promoter region of $O s W R K Y 4$, which activates defense response against Rhizoctonia solani. Moreover, OsWRKY7, OsWRKY58, OsWRKY64, and OsWRKY76 genes are expressed in response to rice blast disease [19]. Overexpression of VaERF20 increases resistance against Pseudomonas syringae and Botrytis cinerea in transgenic Arabidopsis [114]. SlCabZIP and SlERF11 eliminates pathogenicity of Pseudomonas syringae Pv. tomato DC3000 and provide resistance [115]. AtNAC032 represses activation of MYC on pest attack by blocking a coronatine mediated reopening of stomata to thus stopping the entry of Pseudomonas syringae Pv. tomato DC3000 [116]. GhWRKY39-1 provides resistance to Root rot (R. solani) in Gossypium hirsutum [117]. CaWRKY27, CaWRKY6 mediate bacterial wilt while CaWRKY58 resists bacterial spot (Xanthomonas axonopodis) [5]. SINAC35 counter bacterial wilt ( $R$. solanacearum) and bacterial spot (X. compestris) infections in Capsicum annuum [19], as explained in Table 2.

\subsection{Fungal diseases}

Economically important fungal diseases are yellow rust, leaf rust, stem rust, spot rust, red rot, sheath blight, rice blast, powdery mildew, downy mildew, and stem canker. Fungal infestation prevents closing of the stomata, damages the xylem cells, disrupt the cuticle layer, causes extensive water loss, decreases leaf and shoot water potential, decrease fresh weight, root number, and length, produces large numbers of brown roots, and reduces uptake and availability of nutrients [118]. When plants are subject to fungal attacks, they produce plant hormones, i.e., ethylene, salicylic acid, and jasmonic acid. Plant hormones activates expression of TFs, i.e., AP2/ERF, WRKY, NAC, MYB, and MYC [119]. Overexpression of AtWRKY72 enhances resistance against powdery mildew. Similarly, AtWRKY8 and AtWRKY28 enhance resistance against Botrytis cinerea. TaWRKY49, TaWRKY62, and TaWRKY70 combat strip rust (Puccinia strifformis) by activating ROS, jasmonic acid, salicylic acid, and ethylene production [117].

In rice, overexpression of $O s W R K Y 45$ and $O s W R K Y 22$ enhance resistance to Pyricularia oryzae. OsWRKY45 overexpresses and enhances resistance against fungal pathogen Magnaporthe grisea. $O s W R K Y 4$ and $O s W R K Y 80$ increase sheath blight resistance in rice. OsWRKY8O binds to the W-box in the promotor region of OsWRKY4 and works as a positive regulator for Rhizoctonia solani resistance. In Brachpodium distachyon, BdWRKY8, BdWRKY50, BdWRKY34, and BdWRKY70 are upregulated and enhance resistance against Fusarium graminearum. In Hordeum vulgare, HvWRKY1 cooperates with $H v M Y B 6$ to counter powdery mildew [6]. Similarly, TaNAC6 overexpresses and enhances powdery mildew resistance and decreases fungal haustoria. OsNAC6 shows overexpression 
and enhances rice blast resistance. In barley, HvNAC6 overexpresses under powdery mildew infection and increased resistance against Blumeria gramini. VaERF20 increases resistance against Botrytis cinerea in transgenic Arabidopsis. In soybean, GmbZIP1, GmbZIP62, GmbZIP105, and GmbZIP2 genes prevent infestation of Asian soybean rust [19].

\subsection{Viral diseases}

Viruses cause a variety of plant diseases. The main symptoms of all diseases are decreased internodal distance, deficiency of chlorophyll, and reduction in growth. Other related symptoms are reduced germination rate, rolled leaf blade, less nodulation, swelling of stem, tumors on stem, roots and leaves, reduced pollen fertility, less reduced set, wilting, and cell death [120]. Economically important viruses are sorghum mosaic virus (SrMV), sugarcane mosaic virus (SCMV), and sugarcane streak mosaic virus (SCSMV). SrMV and SCMV are effective pathogens for Sorghum bicolor, gramineous plants and Zea mays [121]. Other less virulent viruses are yellow vein mosaic virus in okra, urd bean leaf crinkle virus, strawberry mild yellow edge virus, rice stripe mosaic virus, cotton leaf curl Gezira virus, sugarcane yellow leaf virus, barley yellow dwarf virus, and maize chlorotic mottle virus. Rapid mutations of viral strains is a major factor behind failure of breeding programsm [122]. Plant activate hormonal responses, gene silencing, metabolic regulation, cellular protein degradation by the ubiquitin proteasome pathway (UPS), signaling of immune receptors and PAMP-triggered immunity to stop replication of viruses. Accumulation of ROS and plant hormones, i.e., salicylic acid, jasmonic acid, abscisic acid, brassinosteroids, cytokinin, auxin, ethylene, and gibberellin play role in plant defense against viruses [123].

Different TFs play significant roles into resisting virus-induced damage. Overexpression of OsMYB4 is responsible for resistance against viral diseases. The MtWRKY gene of Medicago truncatula provides resistance against tobacco mosaic virus in Nicotiana tabacum. The Gossypium hirsutum based GhWRKY15 gene, when introduced in Nicotiana tabacum, showed activity against the tobacco mosaic virus [5]. NAC TFs play vital roles in plant immunity by specific signals and virulence action of pathogenic effectors. Viral infection proteins sometime hijack NAC TFs to enable viral replication and decrease host immunity. However, some examples of NAC TFs imparting resistance are as follows: SINAC20, SINAC24, SINAC41, and SINAC61 play a significant role in imparting resistance against Tomato Yellow Leaf Curl Virus (TYLCV) [124]. Triticum aestivum NAC TFs, i.e., AtGRAB1 (Geminivirus Rep A-Binding) and AtGRAB2, interacts with Wheat Dwarf Geminivirus (WDV) Rep A protein and hinder DNA replication of WDV. Arabidopsis thaliana AtAF2 interact with the Tobacco Mosaic Virus (TMV) helicase domain and its overexpression inhibits virus infection [20]. Six WRKY genes, SolyWRKY41, SolyWRKY42, SolyWRKY53, SolyWRKY54, SolyWRKY80, and SolyWRKY81 obtained from tomato reduce TYLCV infection. Interaction analysis provided evidence of interaction between WRKY group III, isochorismate synthase (ICS), and Mitogen-Activated Protein Kinase5 (MAPK) in response to viruses [125].

\subsection{Nematodes}

Plant parasitic nematodes (PPNs) are economically important agricultural pests. Two classes exits i.e., cyst nematodes (CNs) and root knot nematodes (RKNs), causing together an estimated annual loss of US $\$ 80$ billion. PPNs affect a wide range of hosts among economically important crops, i.e., Solanum lycopersicum, Solanum tuberosum, Gossypium hirsutum, Glycine max, Oryza sativa, Zea mays, and Triticum aestivum [126]. PPNs rich in ascaroside (Ascr\# 18) induce the plant immune systems trigger production of jasmonic acid and salicylic acid, as well as trigger PTI and MAPKs. PPN's induce secondary metabolite production in plants, i.e., chlorogenic acid, ethylene, and flavonoids in roots [127]. These secondary metabolites reduce attraction of nematodes towards plant roots. Genes linked with synthesis of cytokinin, gibberellic acid, salicylic acid, jasmonates, and auxin signal responses are activated. SIWRKY75 is activated in Solanum lycopersicum by infection with 
Meloidogyne javanica and stimulate the JA pathway for regulation of the JA signaling mechanism. CsWRKY23 is overexpressed in cucumber plants during infection of Meloidogyne incognita for contributing to early resistance [128].

AtWRKY23 is overexpressed due to auxin stimulation at the feeding point of cyst nematode Heterodera schachtii. OsWRKY11, OsWRKY70, and OsWRKY62 upregulate in response to Hirschmanniella oryza attack. Similarly, OsWRKY13, OsWRKY59, and OsWRKY62 are upregulated against RKN infection. Nineteen WRKY genes in Solanum lycopersicum responded to nematode infection, i.e., upregulation of SlWRKY70 by salicylic acid, both SlWRKY35 and SlWRKY3 were activated [129]. AtWRKY33 is stimulated by JA and works as a positive regulator against PPN attack. AtWRKY33 overexpression along with different promoters confers resistance against Heterodera schachtii. SlWRKY45 is implicated in signal transduction pathways during accumulation of nematodes in the root zone [130]. Five Glycine max WRKY genes of Glycine max; GmWRKY5, GmWRKY28, GmWRKY36, GmWRKY62, and GmWRKY154 are highly responsive against SCN reducing by the $70 \%$ the population, while GmWRKY136, GmWRKY86, GmWRKY53, and GmWRKY52 show moderate response by reducing 40\%-60\% the population and GmWRKY71 and GmWRKY8 caused a 10\%-30\% decline in SCN population [131].

\subsection{Pest attack}

Changing climate is promoting the growth of herbivores, as increased in temperature are shortening life cycles and increasing chances of appearance [132]. Insect possess different feeding mechanisms. Chewing insects such as beetles and caterpillars, consume plant tissues whereas piercing and sucking insects feed on the vascular system for example aphids which inserts their stylets into the phloem. Meanwhile, thrips combine sucking and rasping methods to feed on its host. Some mining type feeders such as larvae of certain beetles, moths, and flies form serpentine cavities when feeding between epidermal cells in leaf tissues and cause twisting or curling of leaves [133]. Moreover, spider mites, a phytophagous acarian belonging to Tetranychus genus, pierce parenchyma cells and suck the contents [134].

Some plants counter attack or activate emergency responses [135]. The plant defense systems are activated when specific pattern recognition receptors (PRRs) detect phytophagous pests through herbivore-associated molecular patterns (HAMPs), microbe-associated molecular patterns (MAMPs), and damage associated molecular patterns (DAMPs). With recognition of molecular patterns, plants activates short-term downstream responses at the membrane levels, i.e., $\mathrm{Ca}^{2+}$ influx, potential depolarization, and generation of ROS or reactive nitrogen species (RNS) as a result, secretion of JA, SA, and ethylene starts, which activates TFs. TFs regulate expression of downstream-located genes through a cascade of CDPKs. These events, of recognition to response, take place within minutes to hours after herbivore attack [133].

Few TFs have been shown to play a role I responding to herbivore induced plant damage. OsERF3 is upregulated in response to feeding of striped stem borer (SSB) in Oryza sativa, which activates the transcript level of two MAPKs and two WRKY genes. As a result, the concentration of SA, JA, and trypsin protease inhibitor activity increases. OsWRKY45 protects rice against infestation by Brown Plant hopper (Nilaparvata lugens) [136]. TaMYB19, TaMYB44, and TaMYB29 act as co-regulators in phloem based defense response against English grain aphid in wheat. AtMYB75 increases resistance against Pieris brassicae by modulating flavonoid metabolites. Overexpression of GsMYB15 obtained from wild soybean increases Arabidopsis resistance against Helicoverpa armigera by a JA mediated insect response [137]. CmMYB19 increases resistance of Chrysanthemum against aphids by promoting a lignin biosynthesis pathway [138]. NbERF173 obtained from Nicotiana benthamiana provides resistance against Phytophthora parasitica [139]. TaWRKY53 induces resistance mechanisms against Russian wheat aphid in Triticum aestivum [140]. Similarly, OsWRKY53 provides resistance against Chilo suppressalis SSB [97]. 
Table 2. Role of different transcriptional factor gene families in biotic stress tolerance in plants.

\begin{tabular}{|c|c|c|c|c|}
\hline Stress & Crop & Disease & Gene & Reference \\
\hline \multirow{11}{*}{ Bacterial } & $\begin{array}{l}\text { Arabidopsis } \\
\text { thaliana }\end{array}$ & $\begin{array}{l}\text { Bacterial Leaf spot } \\
\text { (Pseudomonas syringae) }\end{array}$ & 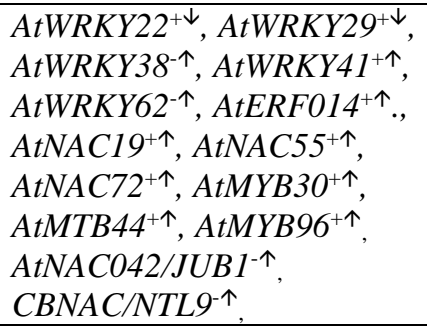 & {$[5,19,20,117]$} \\
\hline & Vitis vinifera & $\begin{array}{l}\text { Bacterial Leaf Spot } \\
\text { (Pseudomonas syringae) }\end{array}$ & $V v E R F 20^{+\uparrow}$ & {$[5,117]$} \\
\hline & Oryza sativa & $\begin{array}{l}\text { Bacterial Blight } \\
\text { (Xanthomonas oryzae) }\end{array}$ & 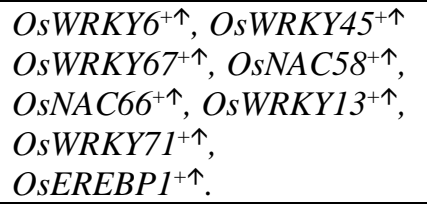 & {$[5,19,20,117]$} \\
\hline & \multirow{3}{*}{ Capsicum anпuиm } & $\begin{array}{l}\text { Bacterial Wilt (Ralstonia } \\
\text { solanacearum) }\end{array}$ & CaWRKY $27^{+\uparrow}$, CaWRKY $Y 6^{+\uparrow}$, & {$[5]$} \\
\hline & & $\begin{array}{l}\text { Bacterial Spot } \\
\text { (Xanthomonas axonopodis) }\end{array}$ & CaWRKY58-^ & {$[5]$} \\
\hline & & $\begin{array}{l}\text { Pepper Root Rot (Bacillus } \\
\text { thuringiensis) }\end{array}$ & $\mathrm{CaPF1} 1^{+\uparrow}$ & {$[117]$} \\
\hline & \multirow{2}{*}{$\begin{array}{l}\text { Solanum } \\
\text { lycopersicum }\end{array}$} & $\begin{array}{l}\text { Bacterial Wilt (Ralstonia } \\
\text { solanacearum) }\end{array}$ & $\begin{array}{l}\text { SlERF3 }^{+\uparrow}, \text { SlERF5 }^{+\uparrow} \\
\text { SlNAC35 }\end{array}$ & {$[5]$} \\
\hline & & $\begin{array}{l}\text { Bacterial Spot } \\
\text { (Xanthomonas campestris) }\end{array}$ & SIERF $1^{+\uparrow}$, SINAC35+^ & {$[5]$} \\
\hline & Glycine $\max$ & $\begin{array}{l}\text { Bacterial Wilt (Ralstonia } \\
\text { solanacearum) }\end{array}$ & $G m E R F 3^{+\uparrow}$ & {$[5]$} \\
\hline & $\begin{array}{l}\text { Nicotiana } \\
\text { tabacum }\end{array}$ & $\begin{array}{l}\text { Bacterial wilt (Ralstonia } \\
\text { solanacearum) }\end{array}$ & $N t W R K Y 50^{+\uparrow}$ & {$[117]$} \\
\hline & Manihot esculenta & $\begin{array}{l}\text { Bacterial Blight } \\
\text { (Xanthomonas axonopodis) }\end{array}$ & MebZIP3 $^{+\uparrow}$, MebZIP5 $^{+\uparrow}$ & {$[5]$} \\
\hline \multirow{10}{*}{ Fungal } & \multirow{3}{*}{$\begin{array}{l}\text { Arabidopsis } \\
\text { thaliana }\end{array}$} & $\begin{array}{l}\text { Gray mold (Botrytis } \\
\text { cinerea) }\end{array}$ & AtERF $1^{+, \uparrow}$, AtERF $14^{+, \uparrow}$ & {$[19]$} \\
\hline & & $\begin{array}{l}\text { Fusarium wilt (Fusariuum } \\
\text { oxysporum) }\end{array}$ & $A t E R F 2^{+, \uparrow}, A t E R F 4^{-\downarrow}$ & {$[19]$} \\
\hline & & $\begin{array}{l}\text { Powdery Mildew (Erysiphe } \\
\text { cruciferarum) }\end{array}$ & AtbZIP10 $10^{+\uparrow}$ & {$[5]$} \\
\hline & \multirow{5}{*}{ Triticum aestivum } & $\begin{array}{l}\text { Yellow Rust (Puccinia } \\
\text { striiformis) }\end{array}$ & 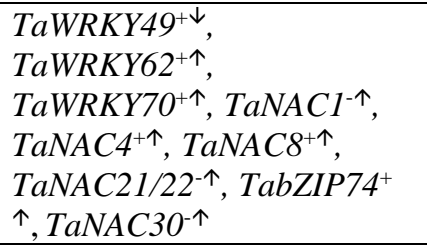 & {$[5,141]$} \\
\hline & & $\begin{array}{l}\text { Leaf rust (Puccinia } \\
\text { triticina) }\end{array}$ & TaWRKYIB ${ }^{+}$ & {$[142]$} \\
\hline & & $\begin{array}{l}\text { Powdery mildew (Erysiphe } \\
\text { cruciferarum) }\end{array}$ & $\begin{array}{l}\text { TaNAC6 }^{+\uparrow},{\text { TaNAC } 21 / 22^{-\uparrow}} \\
\text { TaNAC30 }\end{array}$ & {$[143]$} \\
\hline & & $\begin{array}{l}\text { Root Rot (Bipolaris } \\
\text { sorokiniana) }\end{array}$ & TaERF3- ${ }^{-}$, TaPIEP1 $^{+\uparrow}$ & {$[19]$} \\
\hline & & (Rhizoctonia cerealis) & TaRIMI $^{+\uparrow}$ & [19] \\
\hline & \multirow{2}{*}{ Oryza sativa } & $\begin{array}{l}\text { Sheath blight (Rhizoctonia } \\
\text { solani) }\end{array}$ & OsWRKY4 $4^{+\uparrow}$, OsWRKY $80^{+\uparrow}$ & {$[5]$} \\
\hline & & $\begin{array}{l}\text { Rice Blast (Magnaporthe } \\
\text { oryzae, Pyricularia oryzae) }\end{array}$ & 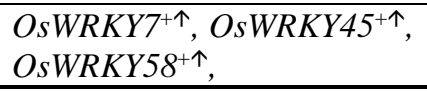 & {$[3,5]$} \\
\hline
\end{tabular}




\begin{tabular}{|c|c|c|c|c|}
\hline & & & 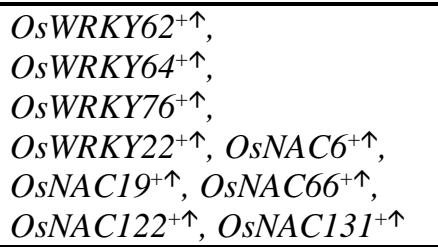 & \\
\hline & $\begin{array}{l}\text { Gossypium } \\
\text { hirsutum }\end{array}$ & $\begin{array}{l}\text { Sheath blight (Rhizoctonia } \\
\text { solani) }\end{array}$ & GhWRKY39-1+^ & {$[5]$} \\
\hline & $\begin{array}{l}\text { Brachpodium } \\
\text { distachyon }\end{array}$ & $\begin{array}{l}\text { Fusarium head blight } \\
\text { (Fusarium graminearum) }\end{array}$ & $\begin{array}{l}B d W R K Y 8^{+\uparrow}, B d W R K Y 34^{+\uparrow}, \\
B d W R K Y 50^{+\uparrow}, \\
B d W R K Y 70^{+\uparrow}, B d W R K Y 69^{+\uparrow}\end{array}$ & {$[5]$} \\
\hline & \multirow{3}{*}{$\begin{array}{l}\text { Solanum } \\
\text { lycopersicum }\end{array}$} & $\begin{array}{l}\text { Gray Mold (Botrytis } \\
\text { cinerea) }\end{array}$ & $S l S R N 1^{-\downarrow}$ & {$[143]$} \\
\hline & & $\begin{array}{l}\text { Tomato Wilt } \\
\text { (Plectosphearella } \\
\text { cucumerina) }\end{array}$ & $S l E R F 1^{+\uparrow}$ & [19] \\
\hline & & $\begin{array}{l}\text { Rhizopus Soft Rot } \\
\text { (Rhizopus nigricans) }\end{array}$ & $S l E R F 1^{+\uparrow}$ & [19] \\
\hline & $\begin{array}{l}\text { Saccharum } \\
\text { officinarum }\end{array}$ & $\begin{array}{l}\text { Red Rot (Colletotrichum } \\
\text { falcatum) }\end{array}$ & $\begin{array}{l}\text { SobZIP4 } 4^{+\uparrow}, \text { SobZIP15 } 5^{+\downarrow}, \\
\text { SoNACH }{ }^{+\downarrow}\end{array}$ & [144] \\
\hline & Solanum tubersum & $\begin{array}{l}\text { Late Blight (Phytophthora } \\
\text { infestans) }\end{array}$ & 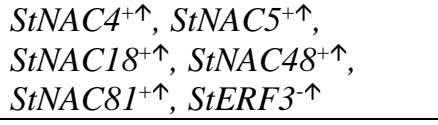 & {$[3,19]$} \\
\hline & \multirow[t]{2}{*}{ Hordium vulgare } & $\begin{array}{l}\text { Powdery mildew (Blumeria } \\
\text { gramini) }\end{array}$ & $\begin{array}{l}H v W R K Y 10^{+\uparrow}, \\
H v W R K Y 19^{+\uparrow}, \\
H v W R K Y 28^{+\uparrow}, H v N A C 6^{-\downarrow}\end{array}$ & {$[5]$} \\
\hline & & $\begin{array}{l}\text { Spot Blotch (Bipolaris } \\
\text { sorokiniana) }\end{array}$ & $H v M Y B 6^{+\uparrow}$ & {$[19]$} \\
\hline & \multirow{2}{*}{ Glycine max } & $\begin{array}{l}\text { Root Rot (Phytophthora } \\
\text { sojae) }\end{array}$ & $G m E R F 5^{+\uparrow}, G m E R F 113^{+\uparrow}$ & [19] \\
\hline & & $\begin{array}{l}\text { Soybean Rust (Phakospora } \\
\text { pachyrhizi) }\end{array}$ & 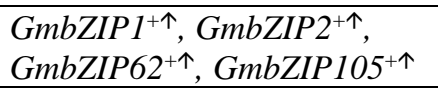 & {$[19]$} \\
\hline & $\begin{array}{l}\text { Nicotiana } \\
\text { benthamiana }\end{array}$ & $\begin{array}{l}\text { Anthracnose } \\
\text { (Colletotrichum orbicular) }\end{array}$ & $N b W R K Y 8^{+\downarrow}$ & {$[5]$} \\
\hline & Vitis vinifera & $\begin{array}{l}\text { Grey Mold (Botrytis } \\
\text { cinerea) }\end{array}$ & $V v E R F 20^{+\uparrow}$ & [19] \\
\hline & $\begin{array}{l}\text { Populus } \\
\text { trichocarpa }\end{array}$ & $\begin{array}{l}\text { Popular leaf Rust } \\
\text { (Melampsora medusae) }\end{array}$ & $\begin{array}{l}\text { PtrWRKY18 } \\
\text { PtrWRKY35 } \\
\text { PtrWRKY } \\
\text { Ptr }\end{array}$ & {$[5]$} \\
\hline \multirow{5}{*}{ Viral } & $\begin{array}{l}\text { Arabidopsis } \\
\text { thaliana }\end{array}$ & $\begin{array}{l}\text { Tobacco mosaic virus } \\
\text { (TMV) }\end{array}$ & 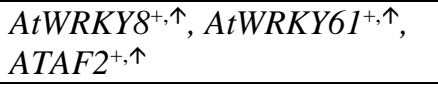 & {$[5,117]$} \\
\hline & $\begin{array}{l}\text { Nicotiana } \\
\text { tobacam }\end{array}$ & $\begin{array}{l}\text { Tobacco mosaic virus } \\
\text { (TMV) }\end{array}$ & $W R K Y 8^{+, \uparrow}, N t E R F 5^{+, \uparrow}$ & {$[5,117]$} \\
\hline & \multirow[b]{2}{*}{ Oryza sativa } & Rice Dwarf Virus (RDV) & $O s N A C^{+, \uparrow}$ & {$[143]$} \\
\hline & & $\begin{array}{l}\text { Rice Stripe Mosaic Virus } \\
\text { (RSMV) }\end{array}$ & $O s M Y B 4^{+, \uparrow}$ & {$[5]$} \\
\hline & $\begin{array}{l}\text { Solanum } \\
\text { lycopersicum }\end{array}$ & $\begin{array}{l}\text { Tomato Yellow Leaf Curl } \\
\text { Virus (TYLCV) }\end{array}$ & 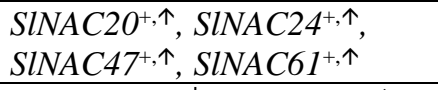 & {$[143]$} \\
\hline \multirow[t]{3}{*}{ Nematodes } & \multirow[t]{2}{*}{$\begin{array}{l}\text { Arabidopsis } \\
\text { thaliana }\end{array}$} & $\begin{array}{l}\text { Cyst nematode (Heterodera } \\
\text { schachtii) }\end{array}$ & 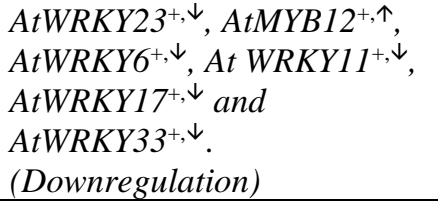 & {$[145]$} \\
\hline & & $\begin{array}{l}\text { Root-Knot Nematodes } \\
\text { (Meloidogyne incognita) }\end{array}$ & $A t M Y B 12^{+, \downarrow}$ & {$[145]$} \\
\hline & $\begin{array}{l}\text { Solanum } \\
\text { lycopersicum }\end{array}$ & $\begin{array}{l}\text { Root Knot Nematode } \\
\text { (Meloidogyne javanica) }\end{array}$ & 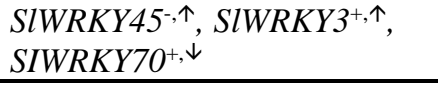 & {$[129,130]$} \\
\hline
\end{tabular}




\begin{tabular}{|c|c|c|c|c|}
\hline & Glycine Max & $\begin{array}{l}\text { Soybean Cyst Nemadtode } \\
\text { (Heterodera glycines) }\end{array}$ & 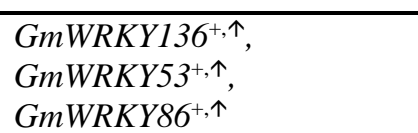 & [146] \\
\hline \multirow{7}{*}{ Insects } & $\begin{array}{l}\text { Arabidopsis } \\
\text { thaliana }\end{array}$ & $\begin{array}{l}\text { Cabbage moth (Pieris } \\
\text { brassicae) }\end{array}$ & $\operatorname{AtMYB75^{+,\uparrow }}$ & [137] \\
\hline & \multirow{2}{*}{ Triticum aestivum } & $\begin{array}{l}\text { English grain aphid } \\
\text { (Sitobion avenae) }\end{array}$ & $\begin{array}{l}\text { TaMYB19 } 9^{+,}, \text {TaMYB2 }^{+, \downarrow}, \\
{\text { TaMYB } 44^{+, \downarrow}}^{-}\end{array}$ & [137] \\
\hline & & $\begin{array}{l}\text { Russian wheat aphid } \\
\text { (Diuraphis noxia) }\end{array}$ & TaWRKY53 $3^{+, \downarrow}$ & [140] \\
\hline & \multirow{3}{*}{ Oryza sativa } & $\begin{array}{l}\text { Brown plant hopper } \\
\text { (Nilaparvata lugens) }\end{array}$ & OsWRKY45 $5^{+, \downarrow}$ & [147] \\
\hline & & \multirow{2}{*}{$\begin{array}{l}\text { Striped stem borer (Chilo } \\
\text { suppressalis) }\end{array}$} & OsWRKY53 $3^{+, \downarrow}$ & [97] \\
\hline & & & $O s E R F 3^{+, \uparrow}$ & {$[136]$} \\
\hline & Chrysanthemum & Aphid (Aphidodea) & $\mathrm{CmMYB15}^{+, \uparrow}, \mathrm{CmMYB19^{+, \uparrow }}$ & {$[138]$} \\
\hline
\end{tabular}

Upward arrow ( $\uparrow$ ) indicates gene upregulation; Downward arrow $(\downarrow)$ indicates gene downregulation; “+” sign indicates positive role of TFs; "“-" sign indicates negative role of TFs, under stress conditions.

\section{Crop Improvement Techniques and TFs}

The implication of TFs from signal perception to signal transduction and expression of stress responsive genes, as summarized in this review. A single TF gene may respond to numerous stresses for example SbNAC58 which is effective against drought, cold, and salinity stress [19]. In view of the crucial role of TFs, they have potential to be exploited using different genome modifying molecular techniques for developing climate resilient crops (Table 3) as explained in Figure 3.

Gene silencing through RNAi provides a platform for exploring the role of different TFs in plant development and in response to various stresses. RNAi uses double-stranded RNA to activate ribonucleases to target homologous mRNA and degrade it. The resulting phenotypes are either null or partially affected. Thus RNAi can help to elucidate role of different TFs under biotic and abiotic stresses [148]. This knowledge can be exploited by incorporating favorable alleles in suitable genetic backgrounds, and using different biotechnological tools, for stress tolerance. RNAi silencing could be used to knockdown TFs, which promote disease development. It can also be useful for knocking out undesirable TFs, which promote the development of stresses. AtNAC042/JUB1, CBNAC/NTL9 promotes bacterial leaf spot of Arabidopsis. Similarly, TaNAC1, TaNAC21/22, TaNAC30 promotes yellow rust and downy mildew attack on wheat. Knockdown these TFs in separate experiments slowed disease development [20].

Different genome editing tools, such as ZF-nucleases (ZFNs), homing endonucleases or mega nucleases, or transcription activator-like effector nucleases (TALENs) create targeted double-strand breaks that promote recombination at a specific locus and have potential in exploring the role of different TFs [149]. Similarly, Clustered Regulatory Interspaced Short Palindromic Repeats (CRISPR) are used to establish knockout lines of TF genes for functional genetics. In the CRISPR/Cas9 system, the genomic target site is cleaved by Cas9, located at the site by the guide RNA (gRNA) with which it complexes. As a result, a double stranded break occurs at the target site, the repair of which causes mutations in the form of insertions or deletions or in some cases frameshifts. These mutants can clarify the role of the TF under consideration [150]. 
Crop improvement techniques
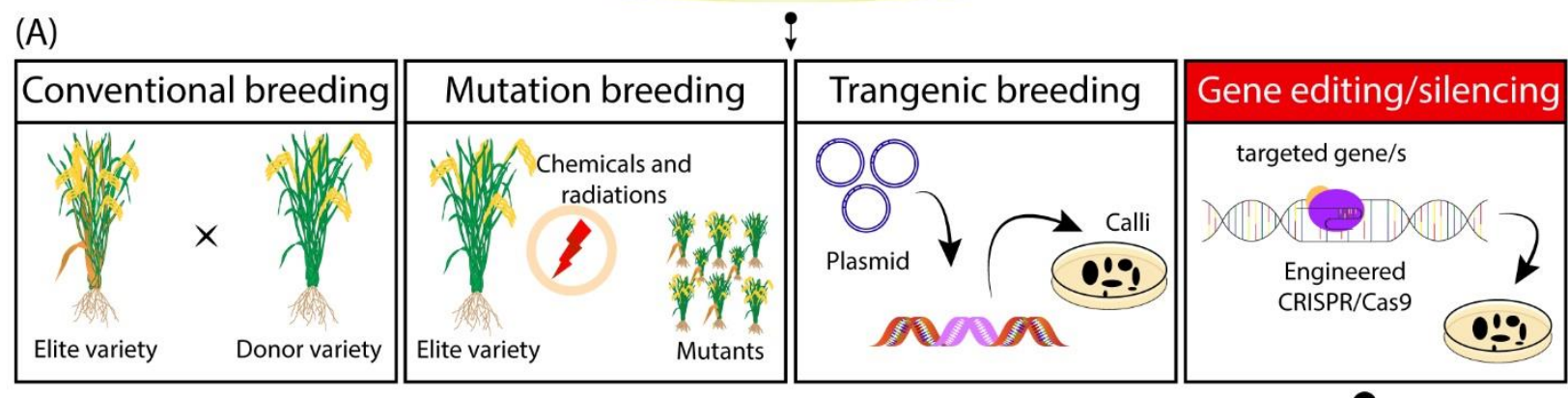

(B)

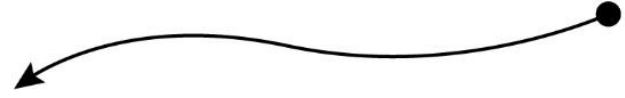

(C) Transcription factors

(D)

\section{MYE}
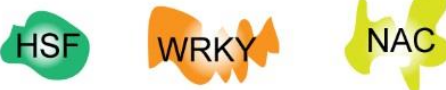

NF-Y

Dof
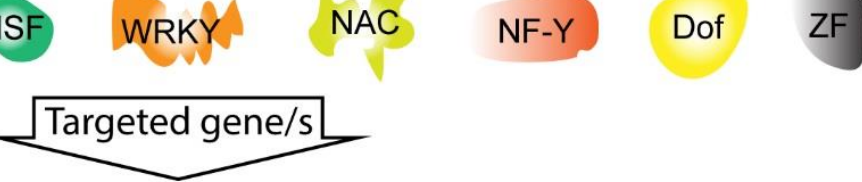

Genome alteration

Biosynthesis

Up/down gene regulation

Harmonal gene transduction

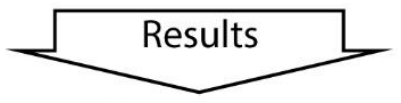

Biotic stress resistance

- Fungal

- Bacterial

- Viral

- Nematode

- Insect pests
Abiotic stress resistance

- Drought

- Salinity

- Heat

- Cold

- Heavy metals

Figure 3. Schematic illustration of different crop improvement techniques particularly targeted modifications in TFs via gene editing/silencing for crop improvement. (A) Overview of different crop improvement techniques. (B) Different transcriptional factors that can be used for incorporation of biotic and abiotic stress tolerance in crops. (C) Different signal transduction pathways that are activated or modified by TFs. (D) Biotic and abiotic stresses that are alleviated by action of TFs.

Table 3. Crop improvement by targeting of TFs through gene silencing and transgenic and gene editing approaches.

\begin{tabular}{ccccc}
\hline Technique & Crop & Gene & Objective & Reference \\
\hline \multirow{4}{*}{ RNAi silencing } & $\begin{array}{c}\text { Arabidopsis } \\
\text { thaliana }\end{array}$ & AtNAC042/JUB1, CBNAC/NTL9 & Bacterial Leaf spot & {$[143]$} \\
\cline { 2 - 5 } & $\begin{array}{c}\text { Triticum } \\
\text { aestivum }\end{array}$ & $\begin{array}{c}\text { TaNAC1, TaNAC21/22, } \\
\text { TaNAC30 }\end{array}$ & $\begin{array}{c}\text { Yellow rust and powdery } \\
\text { mildew resistance }\end{array}$ & {$[143]$} \\
\hline \multirow{3}{*}{ Genome editing } & $\begin{array}{c}\text { Arabidopsis } \\
\text { thaliana }\end{array}$ & AtWRKY11, AtWRKY70 & Pathogen resistance & {$[151]$} \\
\cline { 2 - 5 } & $\begin{array}{c}\text { Triticum } \\
\text { aestivum }\end{array}$ & TaDREB2, TaERF3 & Drought tolerance & {$[106]$} \\
\cline { 2 - 5 } & Oryza sativa & OsNAC2, OsNAC14, OsbZIP62 & Drought tolerance & {$[152]$} \\
\cline { 2 - 5 } & OsERF922 & Rice blast tolerance & {$[151]$} \\
\hline
\end{tabular}




\begin{tabular}{|c|c|c|c|c|}
\hline & Brassica napus & BnWRKY11, BnWRKY70 & Pathogen resistance & [151] \\
\hline \multirow{8}{*}{$\begin{array}{l}\text { Transgenic } \\
\text { approach }\end{array}$} & \multirow{3}{*}{$\begin{array}{l}\text { Arabidopsis } \\
\text { thaliana }\end{array}$} & AtDREBIA, AtWRKY57 & Drought tolerance & \multirow{8}{*}[149,153]{} \\
\hline & & GmbZIP1, GmDREB2, & $\begin{array}{l}\text { Drought, cold, salinity } \\
\text { tolerance }\end{array}$ & \\
\hline & & ZmMYB3R, OsWRKY45 & Drought, salinity tolerance & \\
\hline & \multirow{2}{*}{$\begin{array}{l}\text { Triticum } \\
\text { aestivum }\end{array}$} & AtDREB1A & Drought tolerance & \\
\hline & & GmbZIP1, GhDREB & $\begin{array}{l}\text { Drought, salinity, cold } \\
\text { tolerance }\end{array}$ & \\
\hline & \multirow[t]{2}{*}{ Oryza sativa } & $\begin{array}{c}\text { OsWRKY30, JERF1, OsbZIP23, } \\
\text { OsbZIP46 }\end{array}$ & Drought tolerance & \\
\hline & & SNAC1, SNAC2 & Drought, salinity tolerance & \\
\hline & $\begin{array}{c}\text { Nicotiana } \\
\text { tabacum }\end{array}$ & AtDREB1A, GmERF3 & Drought tolerance & \\
\hline
\end{tabular}

Marker assisted breeding (MAB) has a wide variety of applications in stacking of multiple genes in crop plants for various purposes and had been widely used in studying wheat rust [154]. All we need to find out for marker-assisted breeding is the tight linkage of a molecular marker (with TF as our interest). MAB was used previously for $M d M Y B 1$, associated with apple fruit skin color. MdMYB1 imparts red color to the fruit whereas its absence results in green color. A dCAPS marker was developed for selection of fruit color in apples at early plant developmental stages using MAB [155]. Another very successful example of MAB is the introduction of the SUBI region into rice, which increases submergence tolerance without effecting yield, grain quality or development [156]. Similar marker systems could be developed for WRKY and other TFs responding to under various biotic and abiotic stresses for foreground selection prior to plantation of plants in the field. This will save time and labor, and will facilitate stacking of TF genes for multiple responsiveness in crop plants.

Development of transgenic plants using TFs has a wide variety of potential applications in development of stress tolerant crops. An example is the production of drought tolerant tobacco plants through the use of MdDREB76 from apple [157], or the use of wheat TaNAC29 to enhance salt and drought tolerance in Arabidopsis [158], and many more examples exist in the literature (Table 3). During development of transgenic plants, TFs is most frequently put under the control of a constitutive promotor, i.e., CAMV35S that is expressed in each cell at all growth stages of the plants. Thus, great potential exists for development of transgenic plants using multiple stresses responsive TFs and evaluating their expression in various crops through development of transgenic crops. However, in successive generations of transgenic, rigorous selection criteria should be used to select stress tolerant plants with no negative effects [36].

\section{Ductility and Flexibility in TFs to Carry Out Their Function}

TFs are the most flexible proteins in nature, and this characteristic is very important to conduct regulatory function. It is predicted that $83 \%-94 \%$ of TFs possess extended regions of ductile/disordered residues in eukaryotic organisms. It is observed that organismic complexity is positively and strongly correlated with total number of TFs, the number of their spliced variants, and their total disordered residue content. Transcriptional factor families that take part in cell cycle, cell size, cell proliferation, and cell differentiation have more disordered residues and are more flexible. The evidence suggests that increasing TFs are an important factor for increasing organismic complexity [159]. This ductility of TFs helps plants combat multiple abiotic stress responses by acting as protein chaperones or protecting other cellular components and structures. TFs have complex and versatile networks to efficiently respond to environmental changes. TF disorder plays an important role in plants, providing them with a fast mechanism to obtain complex, interconnected, and versatile molecular networks [160]. 


\section{Future Prospects, Challenges, and Opportunities}

TFs have a great potential for boosting the yield potential and stress tolerance in field crops. Significant achievements have been made in unraveling the potential role of TFs under various biotic and abiotic stresses. However detailed studies of pathways explaining the role of TFs under stress is yet to be explored. Approximately 50 TFs families have been reported with less than ten, i.e., WRKY, DREB, NAC, HSF, MYB, ZF-s, Dof, bZIP, and NAC being functionally characterized under various biotic and abiotic stresses. The Role of the remaining TF families is currently unexplored, which provides a great platform for young researchers to build their future carriers in this field.

There is a need to establish crosstalk between different TF gene families and how they respond under stress conditions [161]. Focus should shift towards development of climate resilient crops with biotic as well as abiotic stress tolerance. In this context, WRKY TFs have a very positive role to play due to their involvement in biotic and abiotic stress tolerance [162]. Not only WRKY, but other TFs also resist biotic as well as abiotic stresses simultaneously. There is a need to identify TF genes that interplay during different stresses. TF genes expressing under multiple stresses should be privileged for breeding climate smart cultivars through conventional as well as modern plant breeding tools.

Transgenic crops promises to be a good source of resistance against biotic and abiotic stresses. However, delivery of TFs to various genetic backgrounds using transgenic technologies still pose a great challenge to researchers due to unexplored metabolic pathways. For this reason, development of transgenic plants using TF candidate genes in crops is not yet fully exploited. Overexpressing some TFs improving stress tolerance can lead to impaired growth responses, i.e., low yield, late flowering, and dwarfing, which is still a challenge to be addressed [163]. Use of tissue specific promotors (SynRI and $S y n R 2$ are root specific) as explained by Ali et al. [164] would help in overcoming the off target affects. Although the majority of TFs play a positive role during different biotic and abiotic stresses. However some genes of NAC TFs promote disease development, i.e., TaNAC1 promotes yellow rust and downy mildew in wheat.

At present most functional studies exploring the role of TFs are conducted in model plants, i.e., tobacco [157] and Arabidopsis [158], which are relatively easy to handle. The focus should be shifted to cultivated crops, i.e., wheat, rice, maize, and other field crops for biotic and abiotic stress tolerance. Although reports are available on transformation of TFs in field crops, however stacking of multiple stresses responsive TFs is just a beginning. Similarly, the role of TFs against heavy metal stress and nematode and insect attacks needs more attention. Another area of improvement is development of functional marker systems, i.e., SSR markers, SNPs, or dCAPS for MAB of different TFs. Only a few examples exist in literature for development of functional marker systems for characterization of TFs [154-156]. Functional markers will help identification of TFs in successive generations for marker-assisted crop improvement.

\section{Conclusions}

Different biotic stresses, i.e., bacterial, fungal and viral diseases, insects and nematodes; and abiotic stresses, i.e., drought, waterlogging, heat, cold, salinity, and heavy metals are becoming an alarming threat to crop productivity with the changing climate. There is an urgent need for development of crops tolerant to biotic and abiotic stresses by targeting different genes and gene families. TFs have emerged as a key potential contributor towards biotic and abiotic stress tolerance in plants, which play a role through signal transduction and activation of stress responsive genes. Different crop improvement approaches, i.e. RNAi silencing, and genome editing promise to deliver safer food to human beings, and ensure food security. Although numerous reports have been available about the use of TFs for crop improvement, the majority of studies are focused on model plants, i.e., Arabidopsis and tobacco. Further, the transgenic plants are frequently evaluated in laboratories under 
artificial conditions without exposing them to natural environmental conditions for their whole life span. Little is known about engineering of multiple TFs for response against multiple biotic and abiotic stresses. In particular, WRKY TFs have diversified roles in biotic and abiotic stress events that need to be elucidated using different omics approaches to explore the mechanisms underlying these complex responses.

\section{Conflict of Interest}

The authors declare that the research was conducted in the absence of any commercial or financial relationships that could be construed as a potential conflict of interest.

\section{Author Contributions}

R.S., S.J., and S.A. conceived the idea. X.W. provided the literature and technical assistance. R.S., S.J., A.N., Z.A., S.S., have drafted the manuscript. S.A., R.S., A.N., and Z.A. have prepared illustrations. R.S., S.A., S.J., M.Z.I., R.T. and R.M.A. have reviewed and improved the draft. All authors listed have made substantial, direct, and intellectual contributions to the work, and approved it for publication.

\section{Funding}

The publication of present work was supported by the National Key Research and Development Program of China (grant no. 2017YFC0504704), and the National Natural Science Foundation of China (51669034, 41761068, 51809224).

\section{Acknowledgments}

The Authors are highly thankful to the colleagues at Maize and Millets Research Institute Yusafwala, Sahiwal, Pakistan, and Ayub Agricultural Research Institute, Faisalabad, Pakistan for time-to-time guidance and moral support. Further advanced apologies to the authors whose work has not been cited due to space issues.

\section{Reference}

1. Mall, R.; Gupta, A.; Sonkar, G. Effect of climate change on agricultural crops. In Current developments in biotechnology and bioengineering, Elsevier: 2017; pp. 23-46.

2. Lan Thi Hoang, X.; Du Nhi, N.H.; Binh Anh Thu, N.; Phuong Thao, N.; Phan Tran, L.-S. Transcription factors and their roles in signal transduction in plants under abiotic stresses. Current genomics 2017, 18, 483-497.

3. Tolosa, L.N.; Zhang, Z. The Role of Major Transcription Factors in Solanaceous Food Crops under Different Stress Conditions: Current and Future Perspectives. Plants 2020, 9, 56.

4. Javed, T.; Shabbir, R.; Ali, A.; Afzal, I.; Zaheer, U.; Gao, S.-J. Transcription Factors in Plant Stress Responses: Challenges and Potential for Sugarcane Improvement. Plants 2020, 9, 491.

5. Erpen, L.; Devi, H.S.; Grosser, J.W.; Dutt, M. Potential use of the DREB/ERF, MYB, NAC and WRKY transcription factors to improve abiotic and biotic stress in transgenic plants. Plant Cell, Tissue and Organ Culture (PCTOC) 2018, $132,1-25$.

6. Jiang, J.; Ma, S.; Ye, N.; Jiang, M.; Cao, J.; Zhang, J. WRKY transcription factors in plant responses to stresses. Journal of integrative plant biology 2017, 59, 86-101.

7. Ülker, B.; Somssich, I.E. WRKY transcription factors: from DNA binding towards biological function. Current opinion in plant biology 2004, 7, 491-498. 
8. Rushton, D.L.; Tripathi, P.; Rabara, R.C.; Lin, J.; Ringler, P.; Boken, A.K.; Langum, T.J.; Smidt, L.; Boomsma, D.D.; Emme, N.J. WRKY transcription factors: key components in abscisic acid signalling. Plant biotechnology journal 2012, 10, 2-11.

9. van Verk, M.C.; Pappaioannou, D.; Neeleman, L.; Bol, J.F.; Linthorst, H.J. A novel WRKY transcription factor is required for induction of PR-1a gene expression by salicylic acid and bacterial elicitors. Plant Physiology 2008, 146, 1983-1995.

10. Eulgem, T.; Rushton, P.J.; Robatzek, S.; Somssich, I.E. The WRKY superfamily of plant transcription factors. Trends in plant science 2000, 5, 199-206.

11. Rushton, P.J.; Somssich, I.E.; Ringler, P.; Shen, Q.J. WRKY transcription factors. Trends in plant science 2010, 15, 247-258.

12. Dubos, C.; Stracke, R.; Grotewold, E.; Weisshaar, B.; Martin, C.; Lepiniec, L. MYB transcription factors in Arabidopsis. Trends in plant science 2010, 15, 573-581.

13. Zhong, R.; Ye, Z.-H. Secondary cell walls: biosynthesis, patterned deposition and transcriptional regulation. Plant and Cell Physiology 2015, 56, 195-214.

14. Sharoni, A.M.; Nuruzzaman, M.; Satoh, K.; Shimizu, T.; Kondoh, H.; Sasaya, T.; Choi, I.-R.; Omura, T.; Kikuchi, S. Gene structures, classification and expression models of the AP2/EREBP transcription factor family in rice. Plant and cell physiology 2011, 52, 344-360.

15. Fujita, Y.; Fujita, M.; Satoh, R.; Maruyama, K.; Parvez, M.M.; Seki, M.; Hiratsu, K.; Ohme-Takagi, M.; Shinozaki, K.; Yamaguchi-Shinozaki, K. AREB1 is a transcription activator of novel ABRE-dependent ABA signaling that enhances drought stress tolerance in Arabidopsis. The Plant Cell 2005, 17, 3470-3488.

16. Chen, H.; Liu, L.; Wang, L.; Wang, S.; Cheng, X. VrDREB2A, a DREB-binding transcription factor from Vigna radiata, increased drought and high-salt tolerance in transgenic Arabidopsis thaliana. Journal of plant research 2016, 129, 263-273.

17. Banerjee, A.; Roychoudhury, A. Abscisic-acid-dependent basic leucine zipper (bZIP) transcription factors in plant abiotic stress. Protoplasma 2017, 254, 3-16.

18. Liao, Y.; Zou, H.-F.; Wei, W.; Hao, Y.-J.; Tian, A.-G.; Huang, J.; Liu, Y.-F.; Zhang, J.-S.; Chen, S.-Y. Soybean GmbZIP44, GmbZIP62 and GmbZIP78 genes function as negative regulator of ABA signaling and confer salt and freezing tolerance in transgenic Arabidopsis. Planta 2008, 228, 225-240.

19. Baillo, E.H.; Kimotho, R.N.; Zhang, Z.; Xu, P. Transcription factors associated with abiotic and biotic stress tolerance and their potential for crops improvement. Genes 2019, 10, 771.

20. Yuan, X.; Wang, H.; Cai, J.; Li, D.; Song, F. NAC transcription factors in plant immunity. Phytopathology Research 2019, 1, 3 .

21. Yanagisawa, S. The Dof family of plant transcription factors. Trends in plant science 2002, 7, 555-560.

22. Noguero, M.; Atif, R.M.; Ochatt, S.; Thompson, R.D. The role of the DNA-binding One Zinc Finger (DOF) transcription factor family in plants. Plant Science 2013, 209, 32-45.

23. Nardini, M.; Gnesutta, N.; Donati, G.; Gatta, R.; Forni, C.; Fossati, A.; Vonrhein, C.; Moras, D.; Romier, C.; Bolognesi, M. Sequence-specific transcription factor NF-Y displays histone-like DNA binding and H2B-like ubiquitination. Cell 2013, 152, 132-143.

24. Petroni, K.; Kumimoto, R.W.; Gnesutta, N.; Calvenzani, V.; Fornari, M.; Tonelli, C.; Holt, B.F.; Mantovani, R. The promiscuous life of plant NUCLEAR FACTOR Y transcription factors. The Plant Cell 2012, 24, 4777-4792.

25. Zhao, H.; Wu, D.; Kong, F.; Lin, K.; Zhang, H.; Li, G. The Arabidopsis thaliana nuclear factor Y transcription factors. Frontiers in Plant Science 2017, 7, 2045.

26. Nover, L.; Bharti, K.; Döring, P.; Mishra, S.K.; Ganguli, A.; Scharf, K.-D. Arabidopsis and the heat stress transcription factor world: how many heat stress transcription factors do we need? Cell stress $\mathcal{E}$ chaperones 2001, 6 , 177.

27. Yura, T.; Nakahigashi, K. Regulation of the heat-shock response. Current opinion in microbiology 1999, 2, $153-158$. 
28. Qiao, X.; Li, M.; Li, L.; Yin, H.; Wu, J.; Zhang, S. Genome-wide identification and comparative analysis of the heat shock transcription factor family in Chinese white pear (Pyrus bretschneideri) and five other Rosaceae species. BMC plant biology 2015, 15, 12.

29. Åkerfelt, M.; Morimoto, R.I.; Sistonen, L. Heat shock factors: integrators of cell stress, development and lifespan. Nature reviews Molecular cell biology 2010, 11, 545-555.

30. Rajavashisth, T.B.; Taylor, A.K.; Andalibi, A.; Svenson, K.L.; Lusis, A.J. Identification of a zinc finger protein that binds to the sterol regulatory element. Science 1989, 245, 640-643.

31. Figueiredo, D.D.; Barros, P.M.; Cordeiro, A.M.; Serra, T.S.; Lourenço, T.; Chander, S.; Oliveira, M.M.; Saibo, N.J. Seven zinc-finger transcription factors are novel regulators of the stress responsive gene OsDREB1B. Journal of experimental botany 2012, 63, 3643-3656.

32. Iuchi, S. Three classes of C2H2 zinc finger proteins. Cellular and Molecular Life Sciences CMLS 2001, 58, 625-635.

33. Kaur, G.; Subramanian, S. Classification of the treble clef zinc finger: noteworthy lessons for structure and function evolution. Scientific reports 2016, 6, 32070.

34. Leng, P.; Zhao, J. Transcription factors as molecular switches to regulate drought adaptation in maize. Theoretical and Applied Genetics 2019, 1-11.

35. Zeid, I.; Shedeed, Z. Response of alfalfa to putrescine treatment under drought stress. Biologia Plantarum 2006, 50, 635.

36. Fahad, S.; Bajwa, A.A.; Nazir, U.; Anjum, S.A.; Farooq, A.; Zohaib, A.; Sadia, S.; Nasim, W.; Adkins, S.; Saud, S. Crop production under drought and heat stress: plant responses and management options. Frontiers in plant science 2017, 8, 1147.

37. Kudo, M.; Kidokoro, S.; Yoshida, T.; Mizoi, J.; Todaka, D.; Fernie, A.R.; Shinozaki, K.; Yamaguchi-Shinozaki, K. Double overexpression of DREB and PIF transcription factors improves drought stress tolerance and cell elongation in transgenic plants. Plant biotechnology journal 2017, 15, 458-471.

38. Yang, J.H.; Lee, K.H.; Du, Q.; Yang, S.; Yuan, B.; Qi, L.; Wang, H. A membrane-associated NAC domain transcription factor XVP interacts with TDIF co-receptor and regulates vascular meristem activity. New Phytologist 2020, 226, 59-74.

39. Wassie, M.; Zhang, W.; Zhang, Q.; Ji, K.; Cao, L.; Chen, L. Exogenous salicylic acid ameliorates heat stressinduced damages and improves growth and photosynthetic efficiency in alfalfa (Medicago sativa L.). Ecotoxicology and Environmental Safety 2020, 191, 110206.

40. Crafts-Brandner, S.J.; Salvucci, M.E. Sensitivity of photosynthesis in a C4 plant, maize, to heat stress. Plant physiology 2002, 129, 1773-1780.

41. Hinojosa, L.; Matanguihan, J.B.; Murphy, K.M. Effect of high temperature on pollen morphology, plant growth and seed yield in quinoa (Chenopodium quinoa Willd.). Journal of agronomy and crop science 2019, 205, 33-45.

42. Hou, H.; Zhao, L.; Zheng, X.; Gautam, M.; Yue, M.; Hou, J.; Chen, Z.; Wang, P.; Li, L. Dynamic changes in histone modification are associated with upregulation of Hsf and rRNA genes during heat stress in maize seedlings. Protoplasma 2019, 256, 1245-1256.

43. Lohani, N.; Golicz, A.A.; Singh, M.B.; Bhalla, P.L. Genome-wide analysis of the Hsf gene family in Brassica oleracea and a comparative analysis of the Hsf gene family in B. oleracea, B. rapa and B. napus. Functional $\mathcal{E}$ integrative genomics 2019, 19, 515-531.

44. Rangan, P.; Furtado, A.; Henry, R. Transcriptome profiling of wheat genotypes under heat stress during grainfilling. Journal of Cereal Science 2020, 91, 102895.

45. Jung, K.-H.; Ko, H.-J.; Nguyen, M.X.; Kim, S.-R.; Ronald, P.; An, G. Genome-wide identification and analysis of early heat stress responsive genes in rice. Journal of Plant Biology 2012, 55, 458-468.

46. Li, S.; Zhou, X.; Chen, L.; Huang, W.; Yu, D. Functional characterization of Arabidopsis thaliana WRKY39 in heat stress. Molecules and cells 2010, 29, 475-483. 
47. Yoshida, T.; Sakuma, Y.; Todaka, D.; Maruyama, K.; Qin, F.; Mizoi, J.; Kidokoro, S.; Fujita, Y.; Shinozaki, K.; Yamaguchi-Shinozaki, K. Functional analysis of an Arabidopsis heat-shock transcription factor HsfA3 in the transcriptional cascade downstream of the DREB2A stress-regulatory system. Biochemical and biophysical research communications 2008, 368, 515-521.

48. Kaymakanova, M. Effect of salinity on germination and seed physiology in bean (Phaseolus vulgaris L.). Biotechnology \& Biotechnological Equipment 2009, 23, 326-329.

49. Shahbaz, M.; Ashraf, M. Does exogenous application of 24-epibrassinolide ameliorate salt induced growth inhibition in wheat (Triticum aestivum L.)? Plant Growth Regulation 2008, 55, 51-64.

50. Hussain, M.I.; Reigosa, M.J. Characterization of xanthophyll pigments, photosynthetic performance, photon energy dissipation, reactive oxygen species generation and carbon isotope discrimination during artemisinininduced stress in Arabidopsis thaliana. PloS one 2015, 10.

51. Shahzad, B.; Fahad, S.; Tanveer, M.; Saud, S.; Khan, I.A. Plant responses and tolerance to salt stress. Approaches for enhancing abiotic stress tolerance in plants. Taylor E Francis 2019, 61-77.

52. Hasegawa, P.M. Sodium (Na+) homeostasis and salt tolerance of plants. Environmental and Experimental Botany 2013, 92, 19-31.

53. Ashrafijou, M.; Noori, S.S.; Darbandi, A.I.; Saghafi, S. Effect of salinity and radiation on proline accumulation in seeds of canola (Brassica napus L.). Plant, Soil and Environment 2010, 56, 312-317.

54. Ciarmiello, L.F.; Woodrow, P.; Piccirillo, P.; De Luca, A.; Carillo, P. Transcription factors and environmental stresses in plants. In Emerging Technologies and Management of Crop Stress Tolerance, Elsevier: 2014; pp. 57-78.

55. Amirbakhtiar, N.; Ismaili, A.; Ghaffari, M.R.; Firouzabadi, F.N.; Shobbar, Z.-S. Transcriptome response of roots to salt stress in a salinity-tolerant bread wheat cultivar. PloS one 2019, 14.

56. He, X.J.; Mu, R.L.; Cao, W.H.; Zhang, Z.G.; Zhang, J.S.; Chen, S.Y. AtNAC2, a transcription factor downstream of ethylene and auxin signaling pathways, is involved in salt stress response and lateral root development. The Plant Journal 2005, 44, 903-916.

57. Finatto, T.; Viana, V.E.; Woyann, L.G.; Busanello, C.; Maia, L.C.d.; Oliveira, A.C.d. Can WRKY transcription factors help plants to overcome environmental challenges? Genetics and molecular biology 2018, 41, 533-544.

58. Du, C.; Zhao, P.; Zhang, H.; Li, N.; Zheng, L.; Wang, Y. The Reaumuria trigyna transcription factor RtWRKY1 confers tolerance to salt stress in transgenic Arabidopsis. Journal of plant physiology 2017, 215, 48-58.

59. Zhou, Q.Y.; Tian, A.G.; Zou, H.F.; Xie, Z.M.; Lei, G.; Huang, J.; Wang, C.M.; Wang, H.W.; Zhang, J.S.; Chen, S.Y. Soybean WRKY-type transcription factor genes, GmWRKY13, GmWRKY21, and GmWRKY54, confer differential tolerance to abiotic stresses in transgenic Arabidopsis plants. Plant biotechnology journal 2008, 6, 486-503.

60. Yang, O.; Popova, O.V.; Süthoff, U.; Lüking, I.; Dietz, K.-J.; Golldack, D. The Arabidopsis basic leucine zipper transcription factor AtbZIP24 regulates complex transcriptional networks involved in abiotic stress resistance. Gene 2009, 436, 45-55.

61. Zheng, X.; Xing, J.; Zhang, K.; Pang, X.; Zhao, Y.; Wang, G.; Zang, J.; Huang, R.; Dong, J. Ethylene response factor ERF11 activates BT4 transcription to regulate immunity to Pseudomonas syringae. Plant physiology 2019, 180, 1132-1151.

62. Hussain, H.A.; Hussain, S.; Khaliq, A.; Ashraf, U.; Anjum, S.A.; Men, S.; Wang, L. Chilling and drought stresses in crop plants: implications, cross talk, and potential management opportunities. Frontiers in plant science 2018, 9, 393.

63. Li, D.; Fu, F.; Zhang, H.; Song, F. Genome-wide systematic characterization of the bZIP transcriptional factor family in tomato (Solanum lycopersicum L.). BMC genomics 2015, 16, 771.

64. Zhang, D.; Guo, X.; Xu, Y.; Li, H.; Ma, L.; Yao, X.; Weng, Y.; Guo, Y.; Liu, C.M.; Chong, K. OsCIPK7 pointmutation leads to conformation and kinase-activity change for sensing cold response. Journal of Integrative Plant Biology 2019, 61, 1194-1200. 
65. Kim, H.J.; Nam, H.G.; Lim, P.O. Regulatory network of NAC transcription factors in leaf senescence. Current opinion in plant biology 2016, 33, 48-56.

66. Liu, M.; Ma, Z.; Sun, W.; Huang, L.; Wu, Q.; Tang, Z.; Bu, T.; Li, C.; Chen, H. Genome-wide analysis of the NAC transcription factor family in Tartary buckwheat (Fagopyrum tataricum). BMC genomics 2019, $20,113$.

67. Su, L.-T.; Li, J.-W.; Liu, D.-Q.; Zhai, Y.; Zhang, H.-J.; Li, X.-W.; Zhang, Q.-L.; Wang, Y.; Wang, Q.-Y. A novel MYB transcription factor, GmMYBJ1, from soybean confers drought and cold tolerance in Arabidopsis thaliana. Gene 2014, 538, 46-55.

68. Maleva, M.; Nekrasova, G.; Borisova, G.; Chukina, N.; Ushakova, O. Effect of heavy metals on photosynthetic apparatus and antioxidant status of Elodea. Russian Journal of Plant Physiology 2012, 59, 190-197.

69. Singh, S.; Parihar, P.; Singh, R.; Singh, V.P.; Prasad, S.M. Heavy metal tolerance in plants: role of transcriptomics, proteomics, metabolomics, and ionomics. Frontiers in plant science 2016, 6, 1143.

70. Chaffei, C. Nitrogen metabolism of tomato under cadmium stress conditions. J. Plant Nutr. 2003, 26, $1617-1634$.

71. Sharma, P.; Jha, A.B.; Dubey, R.S.; Pessarakli, M. Reactive oxygen species, oxidative damage, and antioxidative defense mechanism in plants under stressful conditions. Journal of botany 2012, 2012.

72. Opdenakker, K.; Remans, T.; Vangronsveld, J.; Cuypers, A. Mitogen-activated protein (MAP) kinases in plant metal stress: regulation and responses in comparison to other biotic and abiotic stresses. International journal of molecular sciences 2012, 13, 7828-7853.

73. Jalmi, S.K.; Bhagat, P.K.; Verma, D.; Noryang, S.; Tayyeba, S.; Singh, K.; Sharma, D.; Sinha, A.K. Traversing the links between heavy metal stress and plant signaling. Frontiers in plant science 2018, 9, 12.

74. Zhao, N.; Li, C.; Yan, Y.; Cao, W.; Song, A.; Wang, H.; Chen, S.; Jiang, J.; Chen, F. Comparative transcriptome analysis of waterlogging-sensitive and waterlogging-tolerant Chrysanthemum morifolium cultivars under waterlogging stress and reoxygenation conditions. International journal of molecular sciences 2018, $19,1455$.

75. Sundgren, T.K.; Uhlen, A.K.; Lillemo, M.; Briese, C.; Wojciechowski, T. Rapid seedling establishment and a narrow root stele promotes waterlogging tolerance in spring wheat. Journal of plant physiology 2018, 227, 45-55.

76. Colmer, T.D.; Greenway, H. Ion transport in seminal and adventitious roots of cereals during $\mathrm{O} 2$ deficiency. Journal of Experimental Botany 2011, 62, 39-57.

77. Zhou, W.; Chen, F.; Meng, Y.; Chandrasekaran, U.; Luo, X.; Yang, W.; Shu, K. Plant waterlogging/flooding stress responses: From seed germination to maturation. Plant Physiology and Biochemistry 2020.

78. Barickman, T.C.; Simpson, C.R.; Sams, C.E. Waterlogging causes early modification in the physiological performance, carotenoids, chlorophylls, proline, and soluble sugars of cucumber plants. Plants 2019, 8, 160.

79. Jin, Q.; Xu, Y.; Mattson, N.; Li, X.; Wang, B.; Zhang, X.; Jiang, H.; Liu, X.; Wang, Y.; Yao, D. Identification of submergence-responsive microRNAs and their targets reveals complex miRNA-mediated regulatory networks in lotus (Nelumbo nucifera Gaertn). Frontiers in plant science 2017, 8, 6.

80. Fukao, T.; Barrera-Figueroa, B.E.; Juntawong, P.; Peña-Castro, J.M. Submergence and Waterlogging Stress in Plants: A Review Highlighting Research Opportunities and Understudied Aspects. Frontiers in Plant Science 2019, 10,340 .

81. Borrego-Benjumea, A.; Carter, A.; Tucker, J.R.; Yao, Z.; Xu, W.; Badea, A. Genome-Wide Analysis of Gene Expression Provides New Insights into Waterlogging Responses in Barley (Hordeum vulgare L.). Plants 2020, 9, 240.

82. Dennis, E.S.; Dolferus, R.; Ellis, M.; Rahman, M.; Wu, Y.; Hoeren, F.; Grover, A.; Ismond, K.; Good, A.; Peacock, W. Molecular strategies for improving waterlogging tolerance in plants. Journal of experimental botany 2000, 51, 8997.

83. Yu, F.; Liang, K.; Fang, T.; Zhao, H.; Han, X.; Cai, M.; Qiu, F. A group VII ethylene response factor gene, ZmEREB180, coordinates waterlogging tolerance in maize seedlings. Plant biotechnology journal 2019, 17, 22862298. 
84. Hofmann, N.R. A NAC Transcription Factor for Flooding: SHYG Helps Plants Keep Their Leaves in the Air. Am Soc Plant Biol: 2013.

85. Li, D.; Liu, P.; Yu, J.; Wang, L.; Dossa, K.; Zhang, Y.; Zhou, R.; Wei, X.; Zhang, X. Genome-wide analysis of WRKY gene family in the sesame genome and identification of the WRKY genes involved in responses to abiotic stresses. BMC plant biology 2017, 17, 152.

86. Rashad, Y.M.; Moussa, T.A. Biocontrol Agents for Fungal Plant Diseases Management. In Cottage Industry of Biocontrol Agents and Their Applications, Springer: 2020; pp. 337-363.

87. Sharma, S.; Kooner, R.; Arora, R. Insect pests and crop losses. In Breeding insect resistant crops for sustainable agriculture, Springer: 2017; pp. 45-66.

88. Cerda, R.; Avelino, J.; Gary, C.; Tixier, P.; Lechevallier, E.; Allinne, C. Primary and secondary yield losses caused by pests and diseases: Assessment and modeling in coffee. PloS one 2017, 12.

89. Amorim, A.; Lidiane, L.; da Fonseca dos Santos, R.; Pacifico Bezerra Neto, J.; Guida-Santos, M.; Crovella, S.; Maria Benko-Iseppon, A. Transcription factors involved in plant resistance to pathogens. Current Protein and Peptide Science 2017, 18, 335-351.

90. Tripathi, P.; Rabara, R.C.; Rushton, P.J. A systems biology perspective on the role of WRKY transcription factors in drought responses in plants. Planta 2014, 239, 255-266.

91. Feng, Y.; Yao, Z.; Klionsky, D.J. How to control self-digestion: transcriptional, post-transcriptional, and posttranslational regulation of autophagy. Trends in cell biology 2015, 25, 354-363.

92. Joshi, R.; Wani, S.H.; Singh, B.; Bohra, A.; Dar, Z.A.; Lone, A.A.; Pareek, A.; Singla-Pareek, S.L. Transcription factors and plants response to drought stress: current understanding and future directions. Frontiers in Plant Science 2016, 7, 1029.

93. Kimotho, R.N.; Baillo, E.H.; Zhang, Z. Transcription factors involved in abiotic stress responses in Maize (Zea mays L.) and their roles in enhanced productivity in the post genomics era. PeerJ 2019, 7, e7211.

94. Wei, X.; Lu, W.; Mao, L.; Han, X.; Wei, X.; Zhao, X.; Xia, M.; Xu, C. ABF2 and MYB transcription factors regulate feruloyl transferase FHT involved in ABA-mediated wound suberization of kiwifruit. Journal of experimental botany 2020, 71, 305-317.

95. Li, S.; Li, K.; Ju, Z.; Cao, D.; Fu, D.; Zhu, H.; Zhu, B.; Luo, Y. Genome-wide analysis of tomato NF-Y factors and their role in fruit ripening. BMC genomics 2016, 17, 36.

96. Li, J.; Gao, K.; Khan, W.U.; Yang, X.; Yang, X.; Zhao, T.; Chen, Z.; An, X. Genome-wide analysis of the poplar NFY gene family and its expression in floral bud development of Populus tomentosa. Trees 2020, 34, $285-296$.

97. $\mathrm{Hu}, \mathrm{L} . ;$ Ye, M.; Li, R.; Lou, Y. OsWRKY53, a versatile switch in regulating herbivore-induced defense responses in rice. Plant signaling $\mathcal{E}$ behavior 2016, 11, e1169357.

98. Li, B.; Fan, R.; Yang, Q.; Hu, C.; Sheng, O.; Deng, G.; Dong, T.; Li, C.; Peng, X.; Bi, F. Genome-Wide Identification and Characterization of the NAC Transcription Factor Family in Musa Acuminata and Expression Analysis during Fruit Ripening. International Journal of Molecular Sciences 2020, 21, 634.

99. Shang, X.; Yu, Y.; Zhu, L.; Liu, H.; Chai, Q.; Guo, W. A cotton NAC transcription factor GhirNAC2 plays positive roles in drought tolerance via regulating ABA biosynthesis. Plant Science 2020, 110498.

100. Casaretto, J.A.; El-kereamy, A.; Zeng, B.; Stiegelmeyer, S.M.; Chen, X.; Bi, Y.-M.; Rothstein, S.J. Expression of OsMYB55 in maize activates stress-responsive genes and enhances heat and drought tolerance. BMC genomics 2016, 17, 1-15.

101. Nuruzzaman, M.; Sharoni, A.M.; Kikuchi, S. Roles of NAC transcription factors in the regulation of biotic and abiotic stress responses in plants. Frontiers in microbiology 2013, 4, 248.

102. Guo, M.; Liu, J.-H.; Ma, X.; Luo, D.-X.; Gong, Z.-H.; Lu, M.-H. The plant heat stress transcription factors (HSFs): structure, regulation, and function in response to abiotic stresses. Frontiers in plant science 2016, 7, 114. 
103. Kidokoro, S.; Watanabe, K.; Ohori, T.; Moriwaki, T.; Maruyama, K.; Mizoi, J.; Myint Phyu Sin Htwe, N.; Fujita, Y.; Sekita, S.; Shinozaki, K. Soybean DREB 1/CBF-type transcription factors function in heat and drought as well as cold stress-responsive gene expression. The Plant Journal 2015, 81, 505-518.

104. Yoshida, T.; Fujita, Y.; Sayama, H.; Kidokoro, S.; Maruyama, K.; Mizoi, J.; Shinozaki, K.; Yamaguchi-Shinozaki, K. AREB1, AREB2, and ABF3 are master transcription factors that cooperatively regulate ABRE-dependent ABA signaling involved in drought stress tolerance and require ABA for full activation. The Plant Journal 2010, 61, 672685.

105. Yang, M.; Chao, J.; Wang, D.; Hu, J.; Wu, H.; Gong, D.; Liu, G. Genome-wide identification and expression profiling of the $\mathrm{C} 2 \mathrm{H} 2$-type zinc finger protein transcription factor family in tobacco. Yi chuan= Hereditas 2016, 38, 337-349.

106. Kim, D.; Alptekin, B.; Budak, H. CRISPR/Cas9 genome editing in wheat. Functional E integrative genomics 2018, 18, $31-41$.

107. Moon, S.-J.; Min, M.K.; Kim, J.; Kim, D.Y.; Yoon, I.S.; Kwon, T.R.; Byun, M.O.; Kim, B.-G. Ectopic expression of OsDREB1G, a member of the OsDREB1 subfamily, confers cold stress tolerance in rice. Frontiers in plant science 2019, 10, 297.

108. Yubing, H.; Min, Z.; Lihao, W.; Junhua, W.; Qiaoyan, W.; Rongchen, W.; Yunde, Z. Improvements of TKC technology accelerate isolation of transgene-free CRISPR/Cas9-edited rice plants. Rice Science 2019, 26, $109-117$.

109. Golldack, D.; Lüking, I.; Yang, O. Plant tolerance to drought and salinity: stress regulating transcription factors and their functional significance in the cellular transcriptional network. Plant cell reports 2011, 30, 1383-1391.

110. Li, X.; Guo, C.; Gu, J.; Duan, W.; Zhao, M.; Ma, C.; Du, X.; Lu, W.; Xiao, K. RETRACTED: Overexpression of VP, a vacuolar $\mathrm{H}+$-pyrophosphatase gene in wheat (Triticum aestivum L.), improves tobacco plant growth under Pi and $\mathrm{N}$ deprivation, high salinity, and drought. Journal of experimental botany 2014, 65, 683-696.

111. Li, L.; Zheng, W.; Zhu, Y.; Ye, H.; Tang, B.; Arendsee, Z.W.; Jones, D.; Li, R.; Ortiz, D.; Zhao, X. QQS orphan gene regulates carbon and nitrogen partitioning across species via NF-YC interactions. Proceedings of the National Academy of Sciences 2015, 112, 14734-14739.

112. Ryan, R.P.; Vorhölter, F.-J.; Potnis, N.; Jones, J.B.; Van Sluys, M.-A.; Bogdanove, A.J.; Dow, J.M. Pathogenomics of Xanthomonas: understanding bacterium-plant interactions. Nature Reviews Microbiology 2011, 9, 344-355.

113. Buttimer, C.; McAuliffe, O.; Ross, R.P.; Hill, C.; O’Mahony, J.; Coffey, A. Bacteriophages and bacterial plant diseases. Frontiers in microbiology 2017, 8, 34.

114. Wang, C.-T.; Ru, J.-N.; Liu, Y.-W.; Yang, J.-F.; Li, M.; Xu, Z.-S.; Fu, J.-D. The maize WRKY transcription factor ZmWRKY40 confers drought resistance in transgenic Arabidopsis. International journal of molecular sciences 2018, $19,2580$.

115. Lee, H.; Fischer, R.L.; Goldberg, R.B.; Harada, J.J. Arabidopsis LEAFY COTYLEDON1 represents a functionally specialized subunit of the CCAAT binding transcription factor. Proceedings of the National Academy of Sciences 2003, $100,2152-2156$.

116. Allu, A.D.; Brotman, Y.; Xue, G.P.; Balazadeh, S. Transcription factor ANAC032 modulates JA/SA signalling in response to Pseudomonas syringae infection. EMBO reports 2016, 17, 1578-1589.

117. Chen, F.; Hu, Y.; Vannozzi, A.; Wu, K.; Cai, H.; Qin, Y.; Mullis, A.; Lin, Z.; Zhang, L. The WRKY transcription factor family in model plants and crops. Critical Reviews in Plant Sciences 2017, 36, 311-335.

118. Pandey, P.; Irulappan, V.; Bagavathiannan, M.V.; Senthil-Kumar, M. Impact of combined abiotic and biotic stresses on plant growth and avenues for crop improvement by exploiting physio-morphological traits. Frontiers in plant science $2017,8,537$.

119. Luo, J.; Xia, W.; Cao, P.; Xiao, Z.a.; Zhang, Y.; Liu, M.; Zhan, C.; Wang, N. Integrated transcriptome analysis reveals plant hormones jasmonic acid and salicylic acid coordinate growth and defense responses upon fungal infection in poplar. Biomolecules 2019, 9, 12.

120. Matthews, R. Plant virology; Elsevier: 2012. 
121. Ling, H.; Huang, N.; Wu, Q.; Su, Y.; Peng, Q.; Ahmed, W.; Gao, S.; Su, W.; Que, Y.; Xu, L. Transcriptional insights into the sugarcane-sorghum mosaic virus interaction. Tropical plant biology 2018, 11, 163-176.

122. Jamir, I.; Mandal, A.K.; Devi, A.P.; Bhattacharjee, T.; Maurya, P.K.; Dutta, S.; Chattopadhyay, A.; Pramanik, K.; Banik, S. Screening of genotypes against viral diseases and assessment of yield loss due to yellow vein mosaic virus in okra grown in the eastern part of India. Indian Phytopathology 2020, 1-9.

123. Calil, I.P.; Fontes, E.P. Plant immunity against viruses: antiviral immune receptors in focus. Annals of Botany 2017, 119, 711-723.

124. Huang, Y.; Li, T.; Xu, Z.-S.; Wang, F.; Xiong, A.-S. Six NAC transcription factors involved in response to TYLCV infection in resistant and susceptible tomato cultivars. Plant Physiology and Biochemistry 2017, 120, 61-74.

125. Huangfu, J.; Li, J.; Li, R.; Ye, M.; Kuai, P.; Zhang, T.; Lou, Y. The transcription factor OsWRKY45 negatively modulates the resistance of rice to the brown planthopper Nilaparvata lugens. International journal of molecular sciences 2016, 17, 697 .

126. Warmerdam, S.; Sterken, M.G.; Van Schaik, C.; Oortwijn, M.E.; Sukarta, O.C.; Lozano-Torres, J.L.; Dicke, M.; Helder, J.; Kammenga, J.E.; Goverse, A. Genome-wide association mapping of the architecture of susceptibility to the root-knot nematode Meloidogyne incognita in Arabidopsis thaliana. New Phytologist 2018, 218, $724-737$.

127. Sato, K.; Kadota, Y.; Shirasu, K. Plant immune responses to plant parasitic nematodes. Frontiers in Plant Science 2019, 10, 1165.

128. Macharia, T.N.; Bellieny-Rabelo, D.; Moleleki, L.N. Transcriptional profiling of potato (Solanum tuberosum L.) during a compatible interaction with the root-knot nematode, Meloidogyne javanica. BioRxiv 2019, 849414.

129. Chinnapandi, B.; Bucki, P.; Fitoussi, N.; Kolomiets, M.; Borrego, E.; Braun Miyara, S. Tomato SIWRKY3 acts as a positive regulator for resistance against the root-knot nematode Meloidogyne javanica by activating lipids and hormone-mediated defense-signaling pathways. Plant signaling $\mathcal{E}$ behavior 2019, 14, 1601951.

130. Chinnapandi, B.; Bucki, P.; Braun Miyara, S. SIWRKY45, nematode-responsive tomato WRKY gene, enhances susceptibility to the root knot nematode; M. javanica infection. Plant signaling $\mathcal{E}$ behavior 2017, 12, e1356530.

131. Yang, J.; Zhu, J.; Yang, Y. Genome-wide identification and expression analysis of NF-Y transcription factor families in watermelon (Citrullus lanatus). Journal of Plant Growth Regulation 2017, 36, 590-607.

132. Ximénez-Embún, M.G.; Castañera, P.; Ortego, F. Drought stress in tomato increases the performance of adapted and non-adapted strains of Tetranychus urticae. Journal of insect physiology 2017, 96, 73-81.

133. Santamaria, M.E.; Arnaiz, A.; Gonzalez-Melendi, P.; Martinez, M.; Diaz, I. Plant perception and short-term responses to phytophagous insects and mites. International journal of molecular sciences 2018, 19, 1356.

134. Bensoussan, N.; Santamaria, M.E.; Zhurov, V.; Diaz, I.; Grbić, M.; Grbić, V. Plant-herbivore interaction: dissection of the cellular pattern of Tetranychus urticae feeding on the host plant. Frontiers in plant science 2016, 7, 1105.

135. Santamaria, M.E.; Martínez, M.; Cambra, I.; Grbic, V.; Diaz, I. Understanding plant defence responses against herbivore attacks: an essential first step towards the development of sustainable resistance against pests. Transgenic research 2013, 22, 697-708.

136. Lu, J.; Ju, H.; Zhou, G.; Zhu, C.; Erb, M.; Wang, X.; Wang, P.; Lou, Y. An EAR-motif-containing ERF transcription factor affects herbivore-induced signaling, defense and resistance in rice. The Plant Journal 2011, 68, 583-596.

137. Shen, X.-J.; Wang, Y.-Y.; Zhang, Y.-X.; Guo, W.; Jiao, Y.-Q.; Zhou, X.-A. Overexpression of the wild soybean R2R3MYB transcription factor GsMYB15 enhances resistance to salt stress and Helicoverpa armigera in transgenic Arabidopsis. International journal of molecular sciences 2018, 19, 3958.

138. An, C.; Sheng, L.; Du, X.; Wang, Y.; Zhang, Y.; Song, A.; Jiang, J.; Guan, Z.; Fang, W.; Chen, F. Overexpression of CmMYB15 provides chrysanthemum resistance to aphids by regulating the biosynthesis of lignin. Horticulture research 2019, 6, 1-10.

139. Yu, J.; Chai, C.; Ai, G.; Jia, Y.; Liu, W.; Zhang, X.; Bai, T.; Dou, D. A Nicotiana benthamiana AP2/ERF transcription factor confers resistance to Phytophthora parasitica. Phytopathology Research 2020, 2, 4. 
140. Van Eck, L.; Davidson, R.M.; Wu, S.; Zhao, B.Y.; Botha, A.-M.; Leach, J.E.; Lapitan, N.L. The transcriptional network of WRKY53 in cereals links oxidative responses to biotic and abiotic stress inputs. Functional E integrative genomics 2014, 14, 351-362.

141. Wang, Y.; Zhang, Y.; Zhou, R.; Dossa, K.; Yu, J.; Li, D.; Liu, A.; Mmadi, M.A.; Zhang, X.; You, J. Identification and characterization of the bZIP transcription factor family and its expression in response to abiotic stresses in sesame. PLoS One 2018, 13.

142. Kumar, A.; Jaiswal, J.P.; Sharma, N.; Gupta, S.; Kumar, A. Understanding the molecular basis of differential grain protein accumulation in wheat (Triticum aestivum L.) through expression profiling of transcription factors related to seed nutrients storage. 3 Biotech 2018, 8, 112.

143. Yuan, X.; Wang, H.; Cai, J.; Bi, Y.; Li, D.; Song, F. Rice NAC transcription factor ONAC066 functions as a positive regulator of drought and oxidative stress response. BMC plant biology 2019, 19, 278.

144. Muthiah, M.; Ramadass, A.; Amalraj, R.S.; Palaniyandi, M.; Rasappa, V. Expression profiling of transcription factors (TFs) in sugarcane $X$ Colletotrichum falcatum interaction. Journal of plant biochemistry and biotechnology 2013, 22, 286-294.

145. Hamamouch, N.; Winkel, B.S.; Li, C.; Davis, E.L. Modulation of Arabidopsis Flavonol Biosynthesis Genes by Cyst and Root-Knot Nematodes. Plants 2020, 9, 253.

146. Yang, Y.; Zhou, Y.; Chi, Y.; Fan, B.; Chen, Z. Characterization of soybean WRKY gene family and identification of soybean WRKY genes that promote resistance to soybean cyst nematode. Scientific reports 2017, 7, 1-13.

147. Huang, Y.; Li, M.-Y.; Wu, P.; Xu, Z.-S.; Que, F.; Wang, F.; Xiong, A.-S. Members of WRKY Group III transcription factors are important in TYLCV defense signaling pathway in tomato (Solanum lycopersicum). BMC genomics 2016, 17, 788.

148. Agrawal, N.; Dasaradhi, P.; Mohmmed, A.; Malhotra, P.; Bhatnagar, R.K.; Mukherjee, S.K. RNA interference: biology, mechanism, and applications. Microbiol. Mol. Biol. Rev. 2003, 67, 657-685.

149. Rabara, R.C.; Tripathi, P.; Rushton, P.J. The potential of transcription factor-based genetic engineering in improving crop tolerance to drought. Omics: a journal of integrative biology 2014, 18, 601-614.

150. Ahmad, S.; Wei, X.; Sheng, Z.; Hu, P.; Tang, S. CRISPR/Cas9 for development of disease resistance in plants: recent progress, limitations and future prospects. Briefings in Functional Genomics 2020.

151. Ahmad, S.; Wei, X.; Sheng, Z.; Hu, P.; Tang, S. CRISPR/Cas9 for development of disease resistance in plants: recent progress, limitations and future prospects. Briefings in Functional Genomics 2020, 19, $26-39$.

152. Yang, Z.; Sun, J.; Chen, Y.; Zhu, P.; Zhang, L.; Wu, S.; Ma, D.; Cao, Q.; Li, Z.; Xu, T. Genome-wide identification, structural and gene expression analysis of the bZIP transcription factor family in sweet potato wild relative Ipomoea trifida. BMC genetics 2019, 20, 41.

153. Wu, J.; Lawit, S.J.; Weers, B.; Sun, J.; Mongar, N.; Van Hemert, J.; Melo, R.; Meng, X.; Rupe, M.; Clapp, J. Overexpression of zmm28 increases maize grain yield in the field. Proceedings of the National Academy of Sciences 2019, 116, 23850-23858.

154. Liu, R.; Lu, J.; Zhou, M.; Zheng, S.; Liu, Z.; Zhang, C.; Du, M.; Wang, M.; Li, Y.; Wu, Y. Developing stripe rust resistant wheat (Triticum aestivum L.) lines with gene pyramiding strategy and marker-assisted selection. Genetic Resources and Crop Evolution 2020, 67, 381-391.

155. Zhu, Y.; Evans, K.; Peace, C. Utility testing of an apple skin color MdMYB1 marker in two progenies. Molecular breeding 2011, 27, 525-532.

156. Oladosu, Y.; Rafii, M.Y.; Arolu, F.; Chukwu, S.C.; Muhammad, I.; Kareem, I.; Salisu, M.A.; Arolu, I.W. Submergence Tolerance in Rice: Review of Mechanism, Breeding and, Future Prospects. Sustainability 2020, 12, 1632.

157. Sharma, V.; Goel, P.; Kumar, S.; Singh, A.K. An apple transcription factor, MdDREB76, confers salt and drought tolerance in transgenic tobacco by activating the expression of stress-responsive genes. Plant cell reports 2019, 38, 221-241. 


\section{Transcriptional factor for climate resilient crops}

158. Huang, Q.; Wang, Y.; Li, B.; Chang, J.; Chen, M.; Li, K.; Yang, G.; He, G. TaNAC29, a NAC transcription factor from wheat, enhances salt and drought tolerance in transgenic Arabidopsis. BMC plant biology 2015, 15, 268.

159. Yruela, I.; Oldfield, C.J.; Niklas, K.J.; Dunker, A.K. Evidence for a strong correlation between transcription factor protein disorder and organismic complexity. Genome biology and evolution 2017, 9, 1248-1265.

160. Yruela, I. Plant development regulation: Overview and perspectives. Journal of plant physiology 2015, 182, 62-78.

161. Prasch, C.M.; Sonnewald, U. Signaling events in plants: stress factors in combination change the picture. Environmental and Experimental Botany 2015, 114, 4-14.

162. Bakshi, M.; Oelmüller, R. WRKY transcription factors: Jack of many trades in plants. Plant signaling $\mathcal{E}$ behavior 2014, 9, e27700.

163. Deniaud, E.; Baguet, J.; Chalard, R.; Blanquier, B.; Brinza, L.; Meunier, J.; Michallet, M.-C.; Laugraud, A.; Ah-Soon, C.; Wierinckx, A. Overexpression of transcription factor Sp1 leads to gene expression perturbations and cell cycle inhibition. PloS one 2009, 4.

164. Ali, S.; Kim, W.-C. A fruitful decade using synthetic promoters in the improvement of transgenic plants. Frontiers in plant science 2019, 10. 